\title{
Autoantibodies Against Ro/SS-A, CENP-B, and La/SS-B are Increased in Patients with Kidney Allograft Antibody-Mediated Rejection
}

\author{
Sergi Clotet-Freixas ${ }^{1,2^{*}}$, Max Kotlyar ${ }^{3,4^{*}}$, Caitriona M. McEvoy ${ }^{1,2^{*}}$, Chiara Pastrello ${ }^{3,4^{*}}$, \\ Sonia Rodríguez-Ramírez ${ }^{1}$, Sofia Farkona ${ }^{1,2}$, Heloise Cardinal|5,6, Mélanie Dieudé ${ }^{5,6}$, \\ Marie-Josée Hébert ${ }^{5,6}$, Yanhong Li ${ }^{1}$, Olusegun Famure ${ }^{1}$, Peixuen Chen ${ }^{1}$, S. Joseph \\ $\mathrm{Kim}^{1,6,7}$, Emilie Chan ${ }^{7}$, Igor Jurisica ${ }^{3,4,8,9}$, Rohan John ${ }^{1,10}$, Andrzej Chruscinski ${ }^{1,2,5,6 \#}$, Ana \\ Konvalinka ${ }^{1,2,6,7,10,11 \# .}$ \\ ${ }^{1}$ Toronto General Hospital Research Institute, University Health Network, Toronto, Canada \\ ${ }^{2}$ Soham and Shaila Ajmera Family Transplant Centre, University Health Network, Toronto, Canada \\ ${ }^{3}$ Osteoarthritis Research Program, Division of Orthopedic Surgery, Schroeder Arthritis Institute \\ University Health Network, Toronto, Canada \\ ${ }^{4}$ Krembil Research Institute, University Health Network, Toronto, Canada \\ ${ }^{5}$ Centre de Recherche du Centre Hospitalier de l'Université de Montréal (CHUM), Montreal, Canada \\ ${ }^{6}$ Canadian Donation and Transplantation Research Program, Edmonton, AB, Canada \\ ${ }^{7}$ Department of Medicine, Division of Nephrology, University Health Network, Toronto, Canada \\ ${ }^{8}$ Departments of Medical Biophysics and Computer Science, University of Toronto, Toronto, ON, Canada \\ 9 Institute of Neuroimmunology, Slovak Academy of Sciences, Bratislava, Slovakia \\ ${ }^{10}$ Department of Laboratory Medicine and Pathobiology, University of Toronto, Toronto, Canada \\ ${ }^{11}$ Institute of Medical Science, University of Toronto, Toronto, Canada
}

*Sergi Clotet-Freixas, Max Kotlyar, Caitriona M. McEvoy, and Chiara Pastrello equally contributed to this work

\#Ana Konvalinka and Andrzej Chruscinski equally contributed to this work

Running title: Non-HLA Antibodies in Kidney Antibody-Mediated Rejection

Corresponding authors:

Sergi Clotet-Freixas, PhD and Ana Konvalinka MD, PhD, FRCPC

Department of Medicine, Division of Nephrology, University Health Network

585 University Avenue, room 11-PMB-189. M5G 2N2.Toronto, ON, Canada.

Telephone number: +1 (416)340-4800 ext. 6950

Sergi.ClotetFreixas@uhnresearch.ca

Ana.Konvalinka@uhn.ca

Word count: $\mathbf{3 , 4 9 8}$

Key words: Kidney transplantation, Antibody-mediated rejection, mixed rejection, acute cellular rejection, acute tubular necrosis, protein microarray, Donor-specific antibodies, non-HLA antibodies, Autoimmunity, Alloimmunity, Microvascular lesions, Network Analysis. 


\section{ABSTRACT}

Antibody-mediated rejection (AMR) causes $>50 \%$ of late kidney graft losses. Although donorspecific antibodies (DSA) against HLA cause AMR, antibodies against non-HLA antigens are also linked to rejection. Identifying key non-HLA antibodies will improve our understanding of antibodymediated injury.

We analyzed non-HLA antibodies using protein microarrays in sera from 91 kidney transplant patients with AMR, mixed rejection, acute cellular rejection (ACR), or acute tubular necrosis (ATN). IgM and IgG antibodies against 134 non-HLA antigens were measured pre-transplant, at the time of biopsy-proven diagnosis, and post-diagnosis. Findings were validated in 60 kidney transplant patients from an independent cohort.

Seventeen non-HLA antibodies were significantly increased $(p<0.05)$ in AMR and mixed rejection compared to ACR or ATN pre-transplant, nine at diagnosis and six post-diagnosis. AMR and mixed cases showed significantly increased pre-transplant levels of IgG anti-Ro/SS-A and antiCENP-B, compared to ACR. Together with IgM anti-CENP-B and anti-La/SS-B, these antibodies were also significantly increased in AMR/mixed rejection at diagnosis. Increased lgG anti-Ro/SSA and anti-CENP-B pre-transplant and at diagnosis, and IgM anti-La/SS-B at diagnosis, were associated with the presence of microvascular lesions, but not with tubulitis or interstitial/total inflammation. All three antibodies were associated with the presence of class-II DSA $(p<0.05)$. Significantly increased IgG anti-Ro/SS-A in AMR/mixed compared to ACR $(p=0.01)$, and numerically increased IgM anti-CENP-B $(p=0.05)$ and anti-La/SS-B $(p=0.06)$, were validated in the independent cohort.

This is the first study that implicates autoantibodies against Ro/SS-A and CENP-B in AMR. These non-HLA antibodies may participate in the crosstalk between autoimmunity and alloimmunity in kidney AMR. 


\section{SIGNIFICANCE STATEMENT}

Antibody-mediated rejection (AMR) causes $>50 \%$ of kidney graft losses. Although donor-specific antibodies against HLA cause AMR, antibodies against non-HLA antigens are also linked to rejection. Serum samples of 91 kidney transplant patients were analyzed using protein arrays against 134 non-HLA antigens. AMR and mixed rejection cases showed significantly increased pre-transplant levels of IgG anti-Ro/SS-A and anti-CENP-B, compared to acute cellular rejection. Together with IgM anti-CENP-B and anti-La/SS-B, these antibodies were significantly increased in $A M R / m i x e d$ rejection at diagnosis and were validated in a second, independent cohort. Increased IgG anti-Ro/SS-A, IgG anti-CENP-B and IgM anti-La/SS-B were associated with the presence of microvascular lesions and anti-HLA class-II antibodies. This is the first study to implicate anti-Ro/SS-A, anti-La/SS-B and anti-CENP-B autoantibodies in AMR. 


\section{INTRODUCTION}

Antibody-mediated rejection (AMR) causes $>50 \%$ of late graft failures in kidney transplantation. ${ }^{1}$ AMR is usually caused by antibodies against human leukocyte antigens (HLA). Although histologic findings suggestive of AMR (i.e., microvascular inflammation) are linked to anti-HLAmediated injury, some patients develop these lesions in the absence of anti-HLA donor-specific antibodies (DSA). ${ }^{2-6}$ In turn, not all transplant patients with anti-HLA DSA develop rejection, ${ }^{7}$ suggesting the involvement of other mechanisms in AMR.

Non-HLA allo- or autoantibodies may contribute to the pathogenesis of AMR. Antibodies against vimentin, ${ }^{8,9}$ angiotensin-II type-1 receptor (AT1R),${ }^{2,10-15}$ collagen, ${ }^{16,17}$ fibronectin, ${ }^{16}$ perlecan/LG3, ${ }^{18-}$ ${ }^{21}$ and agrin, ${ }^{5}$ as well as anti-apoptotic cell autoantibodies, ${ }^{22-25}$ are associated with reduced survival and allograft rejection. 2,18,20,26 Non-HLA antibodies are not routinely monitored and their contribution to kidney allograft injury is unclear. Moreover, their dynamic levels and their relationship with cellular rejection or other forms of graft injury remain unknown.

Production of autoantibodies may relate to viral infections, molecular mimicry, cryptic antigen exposure, ${ }^{27-32}$ or as yet unrecognized mechanisms. Autoantibodies produced post-transplant could result from immunotherapy-induced loss of regulatory T-cell proliferation and loss of tolerance to self-antigens. ${ }^{33,34,35}$ While several non-HLA autoantibodies recognized in systemic lupus erythematosus (SLE) and connective tissue disease have been extensively studied in autoimmunity, ${ }^{36-39}$ their role in alloimmunity has not been examined. Yet, autoimmune and alloimmune kidney injury share similarities, especially with regards to vascular injury. ${ }^{40,41}$ Furthermore, both SLE and allograft rejection ${ }^{42}$ are characterized by Th17 responses. ${ }^{43,44}$ There is increasing recognition of the interplay between allo- and autoimmunity, ${ }^{17,23,45}$ and this crosstalk may perpetuate injury. ${ }^{46}$

Our aim was to identify non-HLA antibodies associated with AMR, and to determine their evolution over time and their link to DSA and histopathology lesions. We describe herein a retrospective cohort of 91 kidney transplant patients with 134 non-HLA antibodies measured pre-transplant, at the time of indication biopsy-based diagnosis, and post-diagnosis. Antibodies previously implicated in solid organ transplant injury or autoimmunity were measured using protein arrays. We identified anti-Ro/SS-A(52KDa), anti-CENP-B, and anti-La/SS-B antibodies as significantly increased in kidney transplant recipients with AMR, compared to patients with acute cellular 
bioRxiv preprint doi: https://doi.org/10.1101/2020.12 02 408922; this version posted December 2, 2020. The copyright holder for this preprint

(which was not certified by peer review) is the author/funder, who has granted bioRxiv a license to display the preprint in perpetuity. It is made available under aCC-BY-ND 4.0 International license.

rejection (ACR) or acute tubular necrosis (ATN). These antibodies were associated with class-II DSA and microvascular lesions. We validated these antibodies in an external, independent cohort. This is the first study, to our knowledge, that links autoimmunity-related antibodies to humoral alloimmunity. 


\section{METHODS}

\section{Study Design and Patient Population}

We studied two groups of patients, one for discovery and one for validation. For the discovery phase, we identified kidney transplant recipients at the University Health Network (UHN) in Toronto, with rejection diagnosed between 2008 and 2016, by searching the CoReTRIS registry. ${ }^{47}$ We selected cases with a histological diagnosis of rejection on a for-cause biopsy, and at least one serum sample available in the HLA laboratory. Samples with insufficient volume and/or retrieved within 21 days after the patient received plasmapheresis (PLEX) and/or intravenous immunoglobulin infusion (IVIG) were excluded from further study. Patient exclusion criteria were 1) no serum sample available post-transplant; and 2) all serum samples affected by PLEX and/or IVIG. Finally, we selected cases with ATN that were graft-age matched to AMR and to ACR cases. A renal pathologist (R.J.) scored the biopsies according to the Banff classification (2017). ${ }^{3}$ Twenty-eight of these 91 patients were described in our recent study. ${ }^{48}$ This study was approved by the UHN institutional research ethics board (CAPCR identifier 13-7261).

Serum samples were collected pre-transplant, 'at diagnosis' (within 30 days of the indication biopsy date), and 'post-diagnosis' (collected >30 days after the indication biopsy). The time intervals between the indication biopsy and the post-diagnosis serum collection ranged from 37 days to 2,193 days. The presence of anti-HLA class-I and class-II antibodies in the sera was assessed using Luminex single-antigen bead assays, as part of standard clinical practice. To assess non-HLA antibody levels, we quantified IgG and IgM antibodies against 134 non-HLA antigens, using a VersArray Chipwriter Pro antigen microarray platform (Virtek, Canada). Antigen characteristics are described in Table S1.

For external validation, sera from 60 kidney transplant patients from Center Hospitalier de l'Université de Montréal (CHUM, Montreal) were retrieved 'at diagnosis' (median time of $\leq 4$ days from the indication biopsy). In these samples, IgG and IgM levels against the key non-HLA antibodies identified in the discovery study, were measured using the same microarray platform. The validation cohort was part of a previous study of LG3-related antibodies, and consisted of 29 stable non-rejecting cases, 16 cases with ACR, and 15 cases with acute vascular rejection (AVR), as described previously. ${ }^{49}$ Upon review of the AVR cases, we were able to assign a diagnosis of AMR or mixed rejection ( $n=5), A C R$ grade 2-3 $(n=3)$, and AVR with insufficient information to delineate between AMR and ACR $(n=7)$. The study was approved by the clinical research ethics committee at CHUM (Research Ethics Board number 2008-2545, HD.07.034). 


\section{Histopathology}

Each indication biopsy was embedded in paraffin and $3 \mu \mathrm{m}$ sections were obtained in a microtome (Leica). Sections were then deparaffinized through graded alcohols and subjected to hematoxylin/eosin, trichrome, periodic acid-Schiff, and periodic Schiff-methenamine stains; and examined under a light microscope. Staining of $C 4 d$ was also performed on additional $4 \mu \mathrm{m}$ frozen sections by immunofluorescence. Morphologic features were diagnosed and given a semiquantitative score (0-3) by R.J., according to the updated Banff classification. 3,48

\section{Non-HLA Antigen Microarrays}

\section{Antigen Library and Microarray Generation}

The 134 antigens including proteins, peptides, and cell lysates were diluted to $0.2 \mathrm{mg} / \mathrm{ml}$ in PBS and stored in aliquots at $-80^{\circ} \mathrm{C}$. These antigens were selected because of their importance in autoimmune diseases, ${ }^{50,51}$ or because they were linked to humoral rejection of several organs including kidney, ${ }^{52}$ lung ${ }^{53}$ or heart. ${ }^{54}$ To generate the protein microarrays, the 134 antigens screened in this study were spotted in duplicate onto two-pad FAST nitrocellulose coated slides (Maine Manufacturing, Sanford, ME) using a VersArray Chipwriter Pro microarrayer (Virtek, Toronto, Canada) as previously described. ${ }^{54-56}$ Slides were arrayed using solid pins (Arrayit, Sunnyvale, CA), which generated antigen spots with a diameter of approximately $500 \mu \mathrm{m}$. This process was conducted at 55\% relative humidity and room temperature. Two microarrays were generated on each slide. Nine additional empty spots were measured as blank, to determine the background fluorescence. In both sets of microarrays (discovery and validation), PBS was spotted as negative control, while human IgG (whole molecule and Fc fragment) and human IgM (whole molecule) were spotted to confirm specificity of the anti-lgG and anti-lgM secondary antibodies, respectively.

\section{Sample processing}

The antigen microarray platform was used to screen for $\lg G$ and $\lg M$ against the 134 non-HLA antigens as previously described. ${ }^{54}$ Slides were first dried at room temperature and placed in FAST frames (Maine Manufacturing). Each frame supported a total of 4 slides (8 protein arrays). Microarrays were then incubated overnight with $700 \mu \mathrm{L}$ of blocking buffer (PBS, $5 \% \mathrm{FBS}, 0.1 \%$ Tween) at $4^{\circ} \mathrm{C}$. The following day, blocking buffer was removed and each microarray was 
incubated for 1 hour at $4^{\circ} \mathrm{C}$ with $600 \mu \mathrm{L}$ of a different serum sample at a dilution of $1: 100$ in blocking buffer. A serum sample from a patient with SLE with known pronounced IgG reactivity against Ribo P0, Ribo P1 and Ribo P2, as well as high IgM reactivity against ssDNA and dsDNA, was arrayed as a quality control. Blocking buffer alone was used as a negative control. Microarrays were then washed 3 times for 10 minutes with PBST (PBS and 0.1\% Tween) at room temperature, and subsequently probed with secondary antibodies for 45 minutes at $4^{\circ} \mathrm{C}$. Slides were probed with a mixture of secondary antibodies consisting of Cy3-labeled goat anti-human IgG (Jackson ImmunoResearch, West Grove, PA) at a dilution of 1:2,000 and Cy5-labeled goat anti-human IgM (Jackson ImmunoResearch) at a dilution of 1:1,000. Microarrays were washed again 3 times for 10 minutes with PBST, and slides were dried by centrifugation at 220G for 5 minutes at room temperature. Slides were kept at room temperature and protected from the light until scanning.

To minimize the potential effect of frame-to-frame or day-to-day variability when comparing different study groups, all groups were proportionally represented in each processing day. Samples from the same patient collected at different time points were analyzed in the same frame, to avoid potential batch effects when generating time-course data. Toronto (discovery) and Montreal (validation) cohorts could not be directly compared, since samples were analyzed on different days, and arrays are subject to batch effects.

\section{Quantification of fluorescence intensity}

The fluorescent signals of Cy3 $(\Lambda=532 \mathrm{~nm})$ and Cy5 $(\Lambda=635 \mathrm{~nm})$ were measured on an Axon 4200A microarray scanner (Molecular Devices, Sunnyvale, CA) using a Genepix 6.1 software (Molecular Devices). For each spot, the software calculated the median fluorescent intensity (MFI) minus the local background on the Cy3 and Cy5 channels. To confirm adequate background correction, nine blank spots were also measured in each array. The MFI of each antigen was then determined by averaging the intensity of the duplicate spots. Values of MFI $\geq 200$ in at least one sample were set as detection threshold to further study the antibody signal against a particular antigen. A signal with MFI $\geq 200$ was $>2$ SD from the average MFI of the blanks. As expected, the highest lgG signal across all samples was found at the antigen spots with human lgG (average $\mathrm{MFI}=58,212.59$ ) or human IgG Fc (average MFI = 64,363.63), while the highest IgM signal belonged to the spots with human IgM (average MFI = 51,100.25). 


\section{Data Analysis and Bioinformatics}

\section{Assessment of data distribution}

We evaluated the distributions of all IgG and IgM MFI values in the different diagnoses, and between the sexes. In each patient, a value of zero was given to all antibodies with MFI <200. The log2-transformed MFI values of each antibody in each study group were then used to create density plots using ggplot2 $3.3 .2^{57}$ in $\mathrm{R} 4.0 .2 .^{58}$ Log2-transformed values have been used in subsequent analyses.

\section{Differential antibody levels between types of rejection}

Differential antibody levels analysis of both data sets (discovery and validation) was performed in R. The Wilcoxon-Mann-Whitney nonparametric test was used to assess differences in non-HLA antibody levels between groups. By definition, both AMR and mixed cases show DSA and/or histological signs of antibody-mediated injury. In addition, the distributions of the $\lg \mathrm{G}$ and $\lg \mathrm{M}$ intensity values were comparable between these two forms of rejection. We thus combined the $\mathrm{AMR}$ and the mixed cases in one single 'AMR/mixed' group in the differential antibody MFI analysis, and compared this group to ACR and ATN. This enabled us to enhance the statistical power of the comparative analysis. Data are presented as medians \pm SEM. $P<0.05$ was considered significant.

Antibody changes over time and hierarchical clustering analysis

Log2-transformed MFI values of the non-HLA antibodies with significantly different levels in AMR/mixed patients compared to ACR or ATN were used to generate violin plots of MFI distribution, to visualize antibody changes among groups at different time points. Scatter plots were used to compare MFI trends between the "pre-transplant" and "at diagnosis" time points. Plots were created using ggplot2. Values were then normalized using the formula ( $x$ $\min (x)) /(\max (x)-\min (x))$ and used to build heatmaps with pheatmap 1.0.1259. Unsupervised hierarchical clustering of antibodies and samples was performed using pheatmap with default settings.

\section{Association between non-HLA antibody levels and clinical variables}

Associations between the MFI of non-HLA antibodies (continuous variable) and ordinal histopathology variables based on a semiquantitative 0-3 score (namely vascular fibrous intimal 
thickening, tubulitis, total inflammation, peritubular capillaritis, intimal arteritis, interstitial inflammation, glomerulitis, chronic glomerulopathy, and C4d deposition), were analyzed. Each histopathology variable was split into low (0 or $0-1)$ and high (1-3 or 2-3) categories, and Wilcoxon-Mann-Whitney nonparametric tests were used to assess differences in non-HLA antibody expression between these two categories. Associations between the MFI of non-HLA antibodies and categorical variables (namely presence $=1$ versus absence $=0$ of anti-HLA DSA, anti-HLA class-I DSA and anti-HLA class-II DSA), were also assessed by Wilcoxon-MannWhitney nonparametric tests. All analyses were conducted in $\mathrm{R}$. $\mathrm{P}<0.05$ was considered significant. The most significant associations between all clinical variables and non-HLA antibodies were represented using bubble plots ( $\mathrm{R}$ and ggplot2).

\section{Protein-protein interaction and network analysis}

Physical protein-protein interactions of key non-HLA antibody targets were collected using the Integrated Interactions Database (version 05-2020, http://iid20.ophid.utoronto.ca, https://doi.org/10.1093/nar/gky1037) ${ }^{60}$. Interactions experimentally validated or predicted were retained and visualized using NAViGaTOR 3.0.13 (http://ophid.utoronto.ca/navigator). The gene names of the antibody targets that we previously found to be differentially expressed at the protein level in the AMR glomeruli or tubulointerstitium ${ }^{48}$ are also shown in the network. 


\section{RESULTS}

\section{Study Population}

We studied sera from 43 patients with AMR, 20 patients with mixed rejection, 16 patients with ACR, and 12 patients with ATN (Table 1, Fig. 1A). Most patients were males, except for AMR cases, who had $50 \%$ males. Patients with ATN were significantly older than other groups. The median time between transplantation and diagnostic biopsy was similar in patients with AMR, ACR, and ATN (9.5-15.5 days), but higher among mixed cases (174 days). Most patients with AMR (86\%) or mixed rejection (80\%) had class-I and/or class-II DSA (Table 1). None of the ACR cases had DSA. Although 4/12 ATN patients had DSA, their biopsies did not show signs of rejection (Table 2). Glomerulitis and C4d deposition were detected exclusively among AMR and mixed cases. These two groups showed the highest scores for peritubular capillaritis. The highest interstitial inflammation, tubulitis, and total inflammation were observed in mixed rejection and ACR. Chronic glomerulopathy was found in one mixed and two AMR cases (Table 2).

\section{The Distribution of IgG Antibodies is Conserved Across Time and Diagnoses}

The workflow is shown in Fig. 1B. We analysed 166 serum samples using protein arrays against 134 non-HLA antigens (Table S1). We focused on $119 \mathrm{lgG}$ and $120 \mathrm{lgM}$ antibodies against nonHLA antigens detected with MFI $\geq 200$ in $\geq 1$ sample. We examined the distributions of antibody levels in each group. The distribution of IgG antibodies was remarkably similar among groups and stable across time (Fig. 2A-C). Conversely, IgM antibody levels displayed a shift toward higher levels only in AMR and mixed rejection, at diagnosis (Fig. 2B). Male sex was associated with increased pre-transplant levels of IgG and IgM antibodies (Fig. S1).

\section{Antibodies Against Ro/SS-A, CENP-B, and La/SS-B are Increased in Kidney AMR and Mixed Rejection}

We were predominantly interested in non-HLA antibodies associated with antibody-mediated injury. Interestingly, AMR and mixed rejection groups had analogous $\lg$ and $\lg$ M antibody distributions, emphasizing their similarity (Fig. 2). Among the studied non-HLA antibodies, 36 were significantly altered $(\mathrm{P}<0.05)$ in $\mathrm{AMR} /$ mixed rejection compared to $A C R$ and/or $A T N$, at one or more time points (Table 3 ), being $80 \%$ of them were increased in $A M R /$ mixed rejection. IgG anti-Ro/SS-A(52KDa) and IgG anti-CENP-B were significantly increased in AMR/mixed patients 
compared to ACR, both pre-transplant and at diagnosis. Together with these 2 antibodies, IgM anti-CENP-B, IgM anti-La/SS-B, IgM anti-Ribo P1, and IgM anti-PDH were significantly increased at diagnosis in AMR/mixed patients, compared to ACR. Furthermore, the distributions of IgG antiRo/SS-A(52KDa), IgG and IgM anti-CENP-B, and IgM anti-La/SS-B, were remarkably similar between patients with AMR and mixed rejection, but different from ACR and ATN, and remained consistent across time (Fig. 3A). Hierarchical clustering showed that levels of IgG anti-Ro/SS$\mathrm{A}(52 \mathrm{KDa})$ pre-transplant and at diagnosis clustered with IgG and IgM anti-CENP-B, respectively, and were highest in patients with class-II DSA (Fig.S2A,C). Anti-mitochondrial antibodies against components of the pyruvate dehydrogenase complex, namely IgM anti-PDH and IgG anti-M2 (PCD-E2, OGDC-E2, BCOADC-E2 antigens), were also increased in AMR/mixed compared to ACR and ATN, at diagnosis (Fig. 3A-B, Table 3).

In addition to IgG anti-Ro/SS-A and anti-CENP-B, we found 17 non-HLA antibodies significantly altered before transplant. Fifteen of them were increased in AMR/mixed rejection (Fig. S3, Table 3). Pre-transplant levels of $7 \mathrm{lgG}$ antibodies were significantly higher in AMR/mixed rejection than in ACR, including IgG against ribonucleoprotein SNRPD3, Histidine-tRNA ligase, and Desmin. Compared to ATN, AMR and mixed cases displayed significantly increased pre-transplant levels of 9 non-HLA antibodies, including anti-mitochondrial antibodies IgM anti-OGDC-E2 and IgG anti$\mathrm{PDH}^{61,62}$. AMR/mixed patients also displayed higher pre-existing levels of IgM anti-LG3 ${ }^{49}$, and increased antibodies against lysates of human glomerular microvascular endothelial cells (HGMEC) and cardiac endothelial cells (Fig. S3, Table 3). The distributions of these antibodies were similar between AMR and mixed cases (Fig. S3). Pre-transplant levels of 8 antibodies differed between sexes. While IgM against 3 ssDNA/dsDNA antigens were increased in women, men showed increased levels of IgG against Grp78/BiP, HGMEC lysate, and Asparaginyl-tRNA Synthetase (Table S2).

\section{Intraindividual Variability of Non-HLA Antibodies Over Time}

We next evaluated antibody changes over time. We examined intraindividual changes in the levels of the $14 \mathrm{lgG}$ and $11 \mathrm{lgM}$ antibodies altered in $\mathrm{AMR} /$ mixed rejection pre-transplant and/or at diagnosis. For each antibody, we examined levels at diagnosis compared to pre-transplant. Most IgG antibodies did not fluctuate over time (Fig. S4A). This trend was also observed among $\lg \mathrm{M}$ antibodies, although their intraindividual fluctuations were greater compared to IgG (Fig. S4B). Nonetheless, several AMR and mixed rejection patients displayed an increase in some 
antibodies at diagnosis, including $\operatorname{lgG}$ against Ro/SS-A(52KDa), human $\lg A$, and $M 2$, and $\lg M$ against La/SS-B, PDH, and Ribo P1 (Fig. 3C).

We next determined intergroup differences in antibody levels post-diagnosis. Twelve antibodies were significantly altered between groups. IgG against Troponin I, Thyroglobulin, dsDNA, and IgM anti-ADRB2 were significantly increased in AMR/mixed rejection, compared to ATN (Table

3, Fig. S5). Overall, non-HLA antibodies showed marked intraindividual consistency over time, but some antibodies increased specifically in AMR/mixed rejection at diagnosis.

\section{Non-HLA Antibodies Are Associated with Histopathology Features and DSA}

We examined whether levels of non-HLA antibodies were associated with the presence of histopathological lesions and/or anti-HLA DSA. We focused on 26 non-HLA antibodies pretransplant and 34 antibodies at diagnosis that were significantly and more strongly associated with at least one feature $(\mathrm{P}<0.05)$ (Fig. 4, Table S3).

Increased levels of IgG anti-Ro/SS-A(52KDa) and anti-CENP-B, both pre-transplant and at diagnosis, were significantly associated with the presence of peritubular capillaritis, glomerulitis, intimal arteritis, C4d deposition, and chronic glomerulopathy, but not with tubulitis or interstitial/total inflammation (Fig. 4). Increased pre-transplant levels of IgG and IgM anti-CENPB were significantly associated with the presence of class-I and, more strongly, class-II DSA, while elevated IgG anti-Ro/SS-A(52KDa) was associated predominantly with the presence of class-II DSA (Fig. 4A). At diagnosis, increased levels of IgG anti-Ro/SS-A(52KDa) and IgG antiCENP-B were significantly associated with the presence of class-I/II DSA (Fig. 4B). Accordingly, higher levels of antibodies pre-transplant and/or at diagnosis, but not post-diagnosis, tended to co-cluster with the presence of class-II DSA (Fig. S2). Two other antibodies increased in AMR/mixed rejection at diagnosis, namely IgM anti-La/SS-B and IgG anti-M2, were significantly associated with the presence of glomerulitis, C4d deposition, chronic glomerulopathy, and DSA (Fig. 4B). Interestingly, we found relevant clinical features were significantly associated with IgG against molecular chaperones: while higher lgG anti-HSP90 was linked to the presence of chronic glomerulopathy, increased IgG anti-HSP27 and anti-HSP60 levels were associated with C4d deposition and DSA (Fig. 4B). Few antibodies (6/26 pre-transplant and 13/34 at diagnosis), including IgG anti-dsDNA, IgG anti-HSP60, and IgG anti-Tropomyosin, were significantly and positively associated with tubulitis and/or total inflammation (Fig. 4A). 
External Validation of Antibodies against Ro/SS-A, CENP-B, and La/SS-B in AMR and Mixed Rejection

We next investigated if the observed increases in non-HLA antibodies in AMR/mixed rejection identified in the discovery group (Toronto) could be reproduced in an independent cohort. We conducted external validation of 6 antibodies significantly increased in AMR/mixed cases at diagnosis, namely IgG anti-Ro/SS-A(52 KDa), IgG and IgM anti-CENP-B, IgM anti-La/SS-B, IgM anti-PDH, and IgM anti-Ribo P1. We also interrogated their corresponding IgG or IgM levels (Table S4). We analysed serum samples from a previously described cohort of 60 kidney transplant patients (Montreal) ${ }^{49}$, including patients with AVR, ACR and stable recipients. We were able to reclassify a subgroup of AVR cases as having AMR or mixed rejection, or ACR grade 23. Concordantly with the discovery study, we observed significantly increased levels of IgG antiRo/SS-A(52 KDa, $P=0.008)$ and IgG anti-PDH ( $P=0.02)$, and higher levels of IgG anti-La/SS-B $(P=0.06)$, in $A M R / m i x e d$ compared to $A C R$ patients. When compared to stable controls, AMR/mixed patients still showed significantly increased levels of lgG anti-Ro/SS-A(52KDa, $P=0.004)$ and IgG anti-La/SS-B ( $P=0.02)$, and higher levels of IgG anti-PDH ( $P=0.13)$ (Fig. 5A-

C, Table S4A). The AMR/mixed group also displayed higher levels of IgM anti-CENP-B compared to ACR ( $P=0.06)$ and stable controls $(P=0.05)$ (Fig. 5D). Reassuringly, IgG anti-Ro/SS-A(52KDa) and IgM anti-CENP-B were significantly increased when comparing all cases with AVR with stable controls $(P=0.02$ and $P=0.01$, respectively), and remained elevated when compared to $A C R$ (Table S4B).

\section{Network Analysis Identifies Interactions Between Antibody Targets and Differentially Expressed Proteins in AMR}

Antibodies against HLA and non-HLA antigens interact with proteins expressed by parenchymal cells, including endothelial and epithelial cells. ${ }^{63-67}$ We leveraged our recent proteomics study of glomeruli and tubulointerstitium in grafts with AMR compared to ACR and ATN, ${ }^{48}$ and built a protein-protein interaction network to study the connections between proteins significantly dysregulated in AMR kidneys, and protein targets of key antibodies identified in this study. We focused on targets of antibodies increased in AMR/mixed rejection and externally validated: TRIM21 (target of anti-Ro/SS-A(52KDa)), CENPB (target of anti-CENP-B), SSB (target of antiLa/SS-B), and PDHA1/PDHB (targets of anti-PDH) (Fig. 6). We found direct interactions between TRIM21, HSP90AB1 (increased in AMR glomeruli) and HLADRB1 (increased in AMR tubulointerstitium). ${ }^{48}$ The molecular chaperone HSP90AA1 and the proliferation marker PCNA 
connected with HLA class-I antigens (increased in AMR), ${ }^{48}$ and with antibody targets including centromeric proteins (CENPA, CENPB), metabolic enzymes (PDHA1, PDHB, DLAT, DBST, DBT), and ribosome-related proteins (SSB, RPLP1). The high connectivity between these proteins suggests biological relevance of both the proteins and antibodies directed against them in antibody-mediated injury.

\section{DISCUSSION}

While autoantibodies against Ro/SS-A(52KDa), CENP-B and La/SS-B are elevated and pathogenic in several autoimmune diseases, ${ }^{37,68-70}$ their role in kidney allograft rejection has never been reported. Here, we show that 1) autoantibodies against Ro/SS-A(52KDa), CENP-B and La/SS-B were significantly higher in patients with AMR/mixed rejection compared to ACR at diagnosis; 2) antibodies anti-Ro/SS-A(52KDa) and anti-CENP-B preceded transplantation and increased at the time of $\mathrm{AMR} /$ mixed diagnosis, in both early and late rejections; 3) these antibodies were associated with class-II DSA and microvascular lesions (Fig. 7). Our findings suggest that autoantibodies could participate in kidney allograft injury in AMR.

Despite similar distribution of total IgG and IgM levels between groups, our approach pinpointed specific antibodies significantly altered among different forms of allograft injury. In two independent cohorts, we demonstrated that autoantibodies against Ro/SS-A(52KDa), CENP-B and La/SS-B were increased in patients with $A M R /$ mixed rejection compared to $A C R$, at diagnosis. Ro/SS-A(52KDa) antigen, also known as Ro52 or Tripartite motif-containing protein 21 (TRIM21), is recognized as the Sjögren's syndrome-antigen A(SS-A) ${ }^{71}$, together with Ro60. AntiRo/SS-A antibodies have been described in autoimmune conditions including Sjögren's syndrome, SLE, and systemic sclerosis, and proposed as markers of disease activity. ${ }^{72}$ TRIM21 is an Fc receptor that neutralizes opsonized viral particles entering cells ${ }^{73}$. TRIM21 can be upregulated and translocated to the nucleus under proinflammatory conditions, and modulate type-I interferon expression ${ }^{74}$. TRIM21 can also be expressed on the surface of apoptotic cells and become an immune target ${ }^{75}$. Monocyte surface TRIM21 expression was increased in patients with Sjögren's syndrome, and upregulated by interferon-gamma ${ }^{71}$. Anti-TRIM21 antibodies specifically suppress the anti-inflammatory functions of this protein, while leaving type-I interferon production uncontrolled ${ }^{76}$. Anti-Ro antibodies could thus facilitate and enhance cytokine- and antibody-induced inflammation in AMR. 
Anti-La/SS-B antibodies were elevated at diagnosis in AMR/mixed rejection. La/SS-B regulates cell cycle and binds to RNA polymerase-III transcripts, protecting them from exonucleases. ${ }^{77}$ Like TRIM21, La can be exposed on the surface of apoptotic cells, although it typically resides in the nucleus $^{75}$. Positivity for both anti-Ro/SS-A and anti-La/SS-B antibodies has been observed in SLE and Sjögren's syndrome. ${ }^{37,68,78,79}$ How these autoantibodies are generated is unknown. In mice, immunization with recombinant TRIM21 or La/SS-B resulted in loss of T-cell tolerance towards these antigens, and subsequent activation of B-cells to produce anti-Ro/SS-A and anti-La/SS-B antibodies $^{68}$. The concomitant increase in anti-Ro/SS-A and anti-La/SS-B antibodies in our patients with $\mathrm{AMR} / \mathrm{mixed}$ rejection is consistent with their similarities and associated phenotypes.

We also found significantly increased antibodies against major centromere autoantigen-B (CENPB) in AMR/mixed rejection, compared to ACR. At diagnosis, both $\lg G$ and $\lg M$ anti-CENP-B were elevated in these patients. CENP-B is key to maintain chromosome segregation during mitosis ${ }^{80}$. CENP-B also binds to vascular cells stimulating proliferation, migration, and cytokine release. ${ }^{81,82}$ Anti-centromere antibodies have been described in several autoimmune and inflammatory diseases ${ }^{39,70,83-85}$. Senecal et al. demonstrated that anti-CENP-B antibodies inhibited proliferation and IL-8 production in vascular cells. Aberrant vascular repair and progressive arterial occlusion was observed in the presence of these antibodies ${ }^{81}$. We speculate that these antibodies may have similar effects in AMR.

Antibodies against Ro/SS-A(52KDa) and CENP-B preceded transplantation and increased at the time of $A M R /$ mixed diagnosis, in both early and late rejections. Of note, only three patients in the AMR/Mixed rejection groups had SLE; thus, our observations are not related to pre-transplant autoimmune disease. While these antibodies were virtually absent in ACR, they were detectable in $\mathrm{AMR} / \mathrm{mixed}$ cases, even before transplantation. Longitudinal sera enabled us to note that while all antibodies showed little variability between pre-transplant and at-diagnosis measurements, several antibodies including anti-Ro/SS-A(52KDa), anti-CENP-B and anti-La/SS-B increased at diagnosis compared to pre-transplant. This suggests that these antibodies, similar to anti-AT1R antibodies ${ }^{11}$, predated transplant and were formed by yet unrecognized mechanisms.

AMR and mixed rejection cases were diagnosed after distinct time intervals post-transplant. While pure AMR cases were biopsied within a month post-transplant, mixed rejection cases were diagnosed after a median of 174 days post-transplant. Despite this large difference in the time of diagnosis, the distribution of the anti-Ro/SS-A(52KDa), anti-CENP-B and anti-La/SS-B antibodies 
was remarkably similar in the two groups. This suggests that similar mechanisms are at play in AMR and mixed rejection, regarding the formation of these antibodies and their plausible influence on graft pathology.

Our third major observation was that increased levels of IgG anti-Ro/SS-A(52KDa), anti-CENP-B and IgM anti-La/SS-B were strongly associated with the presence of microvascular lesions and anti-HLA class-II DSA. Class-II DSA are more strongly associated with transplant glomerulopathy, and are considered to be more pathogenic than class-186-88. However, we cannot rule out a stronger association with class-II DSA due to the higher prevalence of these antibodies compared to class-I in the AMR/mixed cohort. Along these lines, levels of IgG anti-Ro/SS-A(52KDa), antiCENP-B and IgM anti-La/SS-B were associated with glomerulitis, C4d deposition and chronic glomerulopathy. Anti-CENP-B and anti-La/SS-B were also associated with intimal arteritis, linking the action of these antibodies in autoimmune diseases to lesions characteristic of AMR. As proposed for other non-HLA antibodies, ${ }^{12,23}$ these antibodies may act in synergy with anti-HLA DSA, enhancing allograft injury.

The targets of these non-HLA and HLA antibodies are highly interconnected in a protein-protein interaction network (Fig. 6). Furthermore, integration with our recent kidney tissue proteomics dataset $^{48}$ highlighted that proteins perturbed in the AMR tissue are directly connected with the targets of the immune response. The key hubs in this network are chaperones HSP90, which participate in renal immunity ${ }^{89}$. HSP90 was previously elevated in the serum of patients with kidney $\mathrm{AMR}^{90}$. We demonstrated that anti-HSP90 antibodies were strongly associated with the presence of chronic glomerulopathy. PCNA is another hub in the network, connecting CENP, $\mathrm{PDH}$ and HSP90 proteins. Upon injury, increased PCNA expression indicates increased cell cycle entry, which may lead to adverse events such as hypertrophy or mitotic catastrophe..$^{91,92}$ In turn, antigen presentation and HLA-ligation can trigger proliferation in endothelial cells. ${ }^{87,93}$ Proliferative stress in kidney AMR may result in abnormal centromere function and affect the turnover of centromere-related proteins, such as CENP-B. In conclusion, proteins disrupted in kidney tissue during AMR interact directly with the targets of anti-HLA and non-HLA antibodies. Further studies aimed at deciphering the biology of these antibodies and their target proteins is warranted.

Our study has several strengths. We investigated a sizeable group of well-characterized kidney transplant recipients, with longitudinally-collected serum samples. Using an innovative protein microarray, we studied non-HLA antibody changes in different subgroups and over time. We 
integrated the findings from this study with clinical/histopathologic data and with our prior proteomics-based study. ${ }^{48}$ The key findings were externally validated. Our study also has limitations. After excluding sera affected by PLEX and/or IVIG, the study of antibody dynamics was limited to a smaller subset of patients. In addition, the time intervals between the indication biopsy date and the post-diagnosis serum were extremely variable, preventing us from including this time point in the study of dynamic changes in antibody levels. Finally, the current study pinpoints novel and interesting associations, but further work is required to establish their causal relationship with AMR.

In conclusion, our approach revealed a novel link between increased pre-transplant levels of lgG anti-Ro/SS-A(52KDa) and anti-CENP-B and the development of AMR after kidney transplantation. Together with IgM anti-La/SS-B, these antibodies were increased in AMR early and late after transplant. All 3 antibodies were associated with the presence of microvascular lesions and anti-HLA class-II DSA, suggesting that they may synergize with class-II DSA and induce endothelial injury in AMR. This is the first effort to date that links specific pre-transplant non-HLA autoantibodies with the diagnosis of AMR after kidney transplantation. 


\section{DISCLOSURES}

All authors have nothing to disclose.

Dr. Igor Jurisica reports receiving personal fees from Canadian Rheumatology Association, grants and nonfinancial support from IBM, and personal fees from Novartis, outside the submitted work.

\section{FUNDING}

AK is supported by Kidney Foundation of Canada Predictive Biomarker grant KFOC160010, the Canadian Institutes of Health Research (CIHR), Canada Foundation for Innovation (CFI) grant 37205, and Kidney Research Scientist Core Education and National Training (KRESCENT) program grants CIHR148204, KRES160004, and KRES160005. AK has also received funding from the Toronto General and Western Hospital Research Foundation (TGTWF 1617-464; TGTWF MKFTR 1718-1268). SC-F is supported by the KRESCENT program (2019KPPDF637713). IJ, CP, and MK were supported in part by Ontario Research Fund grant 34876, Natural Sciences and Engineering Research Council of Canada grant 203475, and CFI grants 29272, 225404, and 30865. HC is a Fonds de recherche du Québec (Santé) Junior 2 scholar.

\section{ACKNOWLEDGEMENTS}

Special thanks to Marc Angeli, Sharon Selvanayagam, and Dr. Uzma Nadeem.

\section{AUTHOR CONTRIBUTIONS}

Dr. Ana Konvalinka conceived the study.

Dr. Ana Konvalinka, Dr. Rohan John, Dr. Andrzej Chruscinski, Dr. Sergi Clotet-Freixas, Dr. Heloise Cardinal, and Dr. Mélanie Dieudé participated in study design. 
Dr. Ana Konvalinka, Dr. Caitriona McEvoy, Dr. Sonia Rodríguez-Ramírez, and Dr. Sergi ClotetFreixas retrieved and curated clinical data from the discovery cohort.

Dr. Heloise Cardinal, Dr. Mélanie Dieudé, and Dr. Marie-Josée Hébert retrieved and curated clinical data from the validation cohort.

Dr. Andrzej Chruscinski and Dr. Sergi Clotet-Freixas performed the experiments.

Dr. Chiara Pastrello, Dr. Max Kotlyar, Dr. Igor Jurisica, Dr. Ana Konvalinka, Dr. Caitriona McEvoy, Dr. Sergi Clotet-Freixas, and Dr. Sofia Farkona analyzed the data.

Dr. Chiara Pastrello, Dr. Max Kotlyar, Dr. Sonia-Rodríguez-Ramírez, and Dr. Sergi Clotet-Freixas made the figures.

Dr. Sergi Clotet-Freixas, Dr. Sonia-Rodríguez-Ramírez, and Dr. Ana Konvalinka drafted and revised the paper; and all authors approved the final version of the manuscript.

Dr. Igor Jurisica reports receiving personal fees from Canadian Rheumatology Association, grants and nonfinancial support from IBM, and personal fees from Novartis, outside the submitted work.

Dr. Caitriona M. McEvoy, Dr. Yanhong Li, Peixuen Chen, and Emilie Chan retrieved and curated clinical data; Dr. Yanhong Li, Dr. Olusegun Famure, and Dr. S. Joseph Kim selected the cases from the CoReTRIS registry and performed case-control matching. 


\section{REFERENCES}

1. Sellarés J, De Freitas DG, Mengel M, et al. Understanding the causes of kidney transplant failure: The dominant role of antibody-mediated rejection and nonadherence. Am J Transplant. 2012;12(2):388-399. doi:10.1111/j.1600-6143.2011.03840.x

2. $\quad$ Duska Dragun, Dominik N Müller, Jan Hinrich Bräsen, Lutz Fritsche, Melina NieminenKelhä, Ralf Dechend, Ulrich Kintscher, Birgit Rudolph, Johan Hoebeke, Diana Eckert, Istvan Mazak, Ralph Plehm, Constanze Schönemann, Thomas Unger, Klemens Budde, Hans-He GW. Angiotensin II type 1-receptor activating antibodies in renal-allograft rejection [4] (multiple letters). N Engl J Med. 2005;352(19):2027-2028. doi:10.1056/NEJM200505123521921

3. Haas M, Loupy A, Lefaucheur C, et al. The Banff 2017 Kidney Meeting Report: Revised diagnostic criteria for chronic active $T$ cell-mediated rejection, antibody-mediated rejection, and prospects for integrative endpoints for next-generation clinical trials. In: American Journal of Transplantation. Vol 18. Blackwell Publishing Ltd; 2018:293-307. doi:10.1111/ajt.14625

4. Sun Q, Cheng Z, Cheng D, et al. De novo development of circulating anti-endothelial cell antibodies rather than pre-existing antibodies is associated with post-transplant allograft rejection. Kidney Int. 2011;79(6):655-662. doi:10.1038/ki.2010.437

5. Joosten SA, Sijpkens YWJ, van Ham V, et al. Antibody response against the glomerular basement membrane protein agrin in patients with transplant glomerulopathy. Am J Transplant. 2005;5(2):383-393. doi:10.1111/j.1600-6143.2005.00690.x

6. Fabrice Porcheray1, Julie DeVito1, Beow Y. Yeap2, Lijuan Xue1, 3, Ian Dargon1, Rosemary Paine1, Timothy C. Girouard4, Susan L. Saidman4, Robert B. Colvin4, Waichi Wong5 and EZ. Chronic humoral rejection of human kidney allografts associates with broad autoantibody. Bone. 2011;23(1):1-7. doi:10.1161/CIRCULATIONAHA.110.956839

7. Butler CL, Valenzuela NM, Thomas KA, Reed EF. Not All Antibodies Are Created Equal: Factors That Influence Antibody Mediated Rejection. J Immunol Res. 2017;2017. doi:10.1155/2017/7903471

8. Rose ML. Role of anti-vimentin antibodies in allograft rejection. Hum Immunol. 2013;74(11):1459-1462. doi:10.1016/j.humimm.2013.06.006

9. Divanyan T, Acosta E, Patel D, Constantino D, Lopez-Soler RI. Anti-vimentin antibodies in transplant and disease. Hum Immunol. 2019;80(8):602-607. doi:10.1016/j.humimm.2019.03.017

10. Pearl MH, Zhang Q, Palma Diaz MF, et al. Angiotensin II Type 1 receptor antibodies are associated with inflammatory cytokines and poor clinical outcomes in pediatric kidney transplantation. Kidney Int. 2018;93(1):260-269. doi:10.1016/j.kint.2017.06.034

11. Min JW, Lee H, Choi BS, et al. Clinical impact of pre-transplant antibodies against angiotensin II type I receptor and major histocompatibility complex class I-related chain a in kidney transplant patients. Ann Lab Med. 2018;38(5):450-457.

doi:10.3343/alm.2018.38.5.450

12. Taniguchi M, Rebellato LM, Cai J, et al. Higher risk of kidney graft failure in the presence of anti-angiotensin II Type-1 receptor antibodies. Am J Transplant. 2013;13(10):25772589. doi:10.1111/ajt.12395

13. Lefaucheur C, Viglietti D, Bouatou Y, et al. Non-HLA agonistic anti-angiotensin II type 1 receptor antibodies induce a distinctive phenotype of antibody-mediated rejection in kidney transplant recipients. Kidney Int. 2019;96(1):189-201. doi:10.1016/j.kint.2019.01.030

14. Gareau AJ, Wiebe C, Pochinco D, et al. Pre-Transplant AT1R Antibodies Correlate with Early Allograft Rejection. Vol 46. Elsevier B.V; 2018. doi:10.1016/j.trim.2017.12.001 
15. Hilbrands L, Hoitsma A, Wetzels J, et al. Angiotensin II type 1-receptor activating antibodies in renal-allograft rejection [4] (multiple letters). $N$ Engl $J$ Med.

2005;352(19):2027-2028. doi:10.1056/NEJM200505123521921

16. Angaswamy N, Klein C, Tiriveedhi V, et al. Immune responses to collagen-IV and fibronectin in renal transplant recipients with transplant glomerulopathy. Am J Transplant. 2014;14(3):685-693. doi:10.1111/ajt.12592

17. Zhang Q, Reed EF. The importance of non-HLA antibodies in transplantation. Nat Rev Nephrol. 2016;12(8):484-495. doi:10.1038/nrneph.2016.88

18. Cardinal H, Dieudé M, Brassard N, et al. Antiperlecan antibodies are novel accelerators of immune-mediated vascular injury. Am J Transplant. 2013;13(4):861-874.

doi:10.1111/ajt.12168

19. Padet L, Dieudé M, Karakeussian-Rimbaud A, et al. New insights into immune mechanisms of antiperlecan/LG3 antibody production: Importance of T cells and innate B1 cells. Am J Transplant. 2019;19(3):699-712. doi:10.1111/ajt.15082

20. Riesco L, Irure J, Rodrigo E, et al. Anti-perlecan antibodies and acute humoral rejection in hypersensitized patients without forbidden HLA specificities after kidney transplantation. Transpl Immunol. 2019;52:53-56. doi:10.1016/j.trim.2018.11.002

21. Lord MS, Tang F, Rnjak-Kovacina J, Smith JGW, Melrose J, Whitelock JM. The multifaceted roles of perlecan in fibrosis. Matrix Biol. 2018;68-69(2017):150-166. doi:10.1016/j.matbio.2018.02.013

22. Zorn E, See SB. Polyreactive natural antibodies in transplantation. Curr Opin Organ Transplant. 2017;22(1):8-13. doi:10.1097/MOT.0000000000000376

23. Cardinal H, Dieudé M, Hébert MJ. The emerging importance of Non-HLA autoantibodies in kidney transplant complications. J Am Soc Nephrol. 2017;28(2):400-406. doi:10.1681/ASN.2016070756

24. See SB, Aubert O, Loupy A, et al. Post-transplant natural antibodies associate with kidney allograft injury and reduced long-term survival. J Am Soc Nephrol. 2018;29(6):1761-1770. doi:10.1681/ASN.2017111157

25. Delville M, Lamarthée B, Pagie S, et al. Early acute microvascular kidney transplant rejection in the absence of anti-HLA antibodies is associated with preformed IgG antibodies against diverse glomerular endothelial cell antigens. J Am Soc Nephrol. 2019;30(4):692-709. doi:10.1681/ASN.2018080868

26. Dieudé M, Cardinal H, Hébert MJ. Injury derived autoimmunity: Anti-perlecan/LG3 antibodies in transplantation. Hum Immunol. 2019;80(8):608-613. doi:10.1016/j.humimm.2019.04.009

27. Dieudé M, Turgeon J, Karakeussian Rimbaud A, et al. Extracellular vesicles derived from injured vascular tissue promote the formation of tertiary lymphoid structures in vascular allografts. Am J Transplant. 2020;20(3):726-738. doi:10.1111/ajt.15707

28. Hardy MP, Audemard É, Migneault F, et al. Apoptotic endothelial cells release small extracellular vesicles loaded with immunostimulatory viral-like RNAs. Sci Rep.

2019;9(1):1-14. doi:10.1038/s41598-019-43591-y

29. Dieudé M, Bell C, Turgeon J, et al. The $20 \mathrm{~S}$ proteasome core, active within apoptotic exosome-like vesicles, induces autoantibody production and accelerates rejection. Sci Trans/ Med. 2015;7(318):1-18. doi:10.1126/scitransImed.aac9816

30. Ramírez-Sandoval R, Sánchez-Rodríguez SH, Herrera-van Oostdam D, Avalos-Díaz E, Herrera-Esparza R. Antinuclear antibodies recognize cellular autoantigens driven by apoptosis. Jt Bone Spine. 2003;70(3):187-194. doi:10.1016/S1297-319X(03)00019-8

31. Suciu-Foca N, Ciubotariu R, Colovai A, et al. Persistent allopeptide reactivity and epitope spreading in chronic rejection. Transplant Proc. 1999;31(1-2):100-101.

doi:10.1016/S0041-1345(98)01458-4

32. Sercarz EE, Lehmann P V, Ametani A, Benichou G, Miller A, Moudgil K. Dominance and 
Crypticity. Published online 1993.

33. Uehara M, McGrath MM. The Role of Costimulatory Pathways in Transplant Tolerance. Clin Lab Med. 2019;39(1):87-106. doi:10.1016/j.cll.2018.10.009

34. Bharat A, Fields RC, Mohanakumar T. Regulatory T Cell - Mediated. Immunol Res. Published online 2005:195-212.

35. Angaswamy N, Tiriveedhi V, Sarma NJ, et al. Interplay between immune responses to HLA and non-HLA self-antigens in allograft rejection. Hum Immunol. 2013;74(11):14781485. doi:10.1016/j.humimm.2013.07.002

36. Meilof JF, Veldhoven CHA, Swaak AJG, Smeenk RJT. Production of anti-Ro/SS-A and anti-La/SS-B autoantibodies is closely coordinated in systemic lupus erythematosus and independent of anti-dsDNA production. J Autoimmun. 1997;10(1):67-75.

doi:10.1006/jaut.1996.0110

37. Pradhan VD, Badakere SS, Bichile LS, Dolas MP. Antibodies to Ro/SS-A and La/SS-B in systemic lupus erythematosus and other autoimmune disorders. J Assoc Physicians India. 2002;50(6):762-765.

38. Hudson M, Mahler M, Pope J, et al. Clinical correlates of CENP-A and CENP-B antibodies in a large cohort of patients with systemic sclerosis. J Rheumatol. 2012;39(4):787-794. doi:10.3899/rheum.111133

39. Gelber AC, Pillemer SR, Baum BJ, et al. Distinct recognition of antibodies to centromere proteins in primary Sjögren's syndrome compared with limited scleroderma. Ann Rheum Dis. 2006;65(8):1028-1032. doi:10.1136/ard.2005.046003

40. Woodworth TG, Suliman YA, Furst DE, Clements P. Scleroderma renal crisis and renal involvement in systemic sclerosis. Nat Rev Nephrol. 2016;12(11):678-691. doi:10.1038/nrneph.2016.124

41. Cohen D, Colvin RB, Daha MR, et al. Pros and cons for C4d as a biomarker. Kidney Int. 2012;81(7):628-639. doi:10.1038/ki.2011.497

42. Oleinika K, Mauri C, Salama AD. Effector and regulatory B cells in immune-mediated kidney disease. Nat Rev Nephrol. 2019;15(1):11-26. doi:10.1038/s41581-018-0074-7

43. Heidt S, San D, Chadha R, Wood KJ. The impact of Th17 cells on transplant rejection and the induction of tolerance. Curr Opin Organ Transplant. 2010;15(4):456-461. doi:10.1097/MOT.0b013e32833b9bfb

44. Antonysamy MA, Fanslow WC, Fu F, et al. Evidence for a role of IL-17 in organ allograft rejection: IL-17 promotes the functional differentiation of dendritic cell progenitors. $J$ Immunol. 1999;162(1):577-584.

45. Steers NJ, Li Y, Drace Z, et al. Genomic mismatch at LIMS1 locus and kidney allograft rejection. N Engl J Med. 2019;380(20):1918-1928. doi:10.1056/NEJMoa1803731

46. Carbone M, Neuberger JM. Autoimmune liver disease, autoimmunity and liver transplantation. J Hepatol. 2014;60(1):210-223. doi:10.1016/j.jhep.2013.09.020

47. Famure O, Phan NA-T, Kim SJ. Health information management for research and quality assurance: the Comprehensive Renal Transplant Research Information System. Healthc Manag forum. 2014;27(1):30-36. doi:10.1016/j.hcmf.2013.11.002

48. Clotet-Freixas S, McEvoy CM, Batruch I, et al. Extracellular Matrix Injury of Kidney Allografts in Antibody-Mediated Rejection: A Proteomics Study. J Am Soc Nephrol. Published online September 8, 2020:ASN.2020030286. doi:10.1681/asn.2020030286

49. Soulez M, Pilon EA, Dieudé M, et al. The perlecan fragment LG3 is a novel regulator of obliterative remodeling associated with allograft vascular rejection. Circ Res.

2012;110(1):94-104. doi:10.1161/CIRCRESAHA.111.250431

50. Quintana FJ, Farez MF, Viglietta V, et al. Antigen microarrays identify unique serum autoantibody signatures in clinical and pathologic subtypes of multiple sclerosis. Proc Natl Acad Sci U S A. 2008;105(48):18889-18894. doi:10.1073/pnas.0806310105

51. Hueber W, Kidd BA, Tomooka BH, et al. Antigen microarray profiling of autoantibodies in 
rheumatoid arthritis. Arthritis Rheum. 2005;52(9):2645-2655. doi:10.1002/art.21269

52. Porcheray F, Devito J, Yeap BY, et al. Chronic humoral rejection of human kidney allografts associates with broad autoantibody responses. Transplantation.

2010;89(10):1239-1246. doi:10.1097/TP.0b013e3181d72091

53. Hagedorn $\mathrm{PH}$, Burton $\mathrm{CM}$, Carlsen $\mathrm{J}$, et al. Chronic rejection of a lung transplant is characterized by a profile of specific autoantibodies. Immunology. 2010;130(3):427-435. doi:10.1111/j.1365-2567.2010.03246.x

54. Chruscinski A, Huang FYY, Nguyen A, et al. Generation of antigen microarrays to screen for autoantibodies in heart failure and heart transplantation. PLoS One. 2016;11(3). doi:10.1371/journal.pone.0151224

55. Balboni I, Limb C, Tenenbaum JD, Utz PJ. Evaluation of microarray surfaces and arraying parameters for autoantibody profiling. Proteomics. 2008;8(17):3443-3449. doi:10.1002/pmic.200800146

56. Singh H, Henry KA, Wu SST, Chruscinski A, Utz PJ, Scott JK. Reactivity profiles of broadly neutralizing anti-HIV-1 antibodies are distinct from those of pathogenic autoantibodies. AIDS. 2011;25(10):1247-1252. doi:10.1097/QAD.0b013e32834785cf

57. Wickham H. Elegant Graphics for Data Analysis. In: Elegant Graphics for Data Analysis. ; 2016:3-10. http://link.springer.com/10.1007/978-3-319-24277-4_1

58. R Foundation for Statistical Computing. R: A language and environment for statistical computing. Vienna, Austria. Published 2014.

http://www.gnu.org/copyleft/gpl.html.\%0Ahttp://www.gbif.org/resource/81287

59. Kolde R. pheatmap: Pretty Heatmaps in R package. $R$ Packag version 61. Published online 2012.

60. Kotlyar M, Pastrello C, Malik Z, Jurisica I. IID 2018 update: context-specific physical protein-protein interactions in human, model organisms and domesticated species. Nucleic Acids Res. 2019;47(D1):D581-D589. doi:10.1093/nar/gky1037

61. Surh CD, Ahmed-Ansari A, Gershwin ME. Comparative epitope mapping of murine monoclonal and human autoantibodies to human PDH-E2, the major mitochondrial autoantigen of primary biliary cirrhosis. J Immunol. 1990;144(7):2647-2652.

62. Antimitochondrial antibodies of primary biliary cirrhosis recognize dihydrolipoamide acyltransferase and inhibit enzyme function of the branched chain alpha-ketoacid dehydrogenase complex - PubMed. Accessed October 28, 2020.

https://pubmed.ncbi.nlm.nih.gov/2715637/

63. Valenzuela NM, Mcnamara JT, Reed EF. Antibody-Mediated Graft Injury: ComplementDependent and Complement-Independent Mechanisms.

doi:10.1097/MOT.0000000000000040

64. Jin Y-P, Valenzuela NM, Zhang X, Rozengurt E, Reed EF. HLA Class II-Triggered Signaling Cascades Cause Endothelial Cell Proliferation and Migration: Relevance to Antibody-Mediated Transplant Rejection. J Immunol. 2018;200(7):2372-2390. doi:10.4049/jimmunol.1701259

65. Valenzuela NM, Reed EF. Antibody-mediated rejection across solid organ transplants: Manifestations, mechanisms, and therapies. J Clin Invest. 2017;127(7):2492-2504. doi:10.1172/JCI90597

66. Egelkamp J, Chichelnitskiy E, Kühne JF, et al. Back signaling of HLA class I molecules and T/NK cell receptor ligands in epithelial cells reflects the rejection-specific microenvironment in renal allograft biopsies. Am J Transplant. 2019;19(10):2692-2704. doi:10.1111/ajt.15417

67. Aljabri A, Vijayan V, Stankov M, et al. HLA class II antibodies induce necrotic cell death in human endothelial cells via a lysosomal membrane permeabilization-mediated pathway. Cell Death Dis. 2019;10(3). doi:10.1038/s41419-019-1319-5

68. Smeenk RJT. RO/SS-A and La/SS-B: Autoantigens in Sjögren's syndrome? Clin 
Rheumatol J Int Leag Assoc Rheumatol. 1995;14(1):11-16. doi:10.1007/BF03342632

69. Mahler M, Mierau R, Genth E, Blüthner M. Development of a CENP-A/CENP-B-specific immune response in a patient with systemic sclerosis. Arthritis Rheum. 2002;46(7):18661872. doi:10.1002/art.10330

70. Mahler M, You D, Baron M, Taillefer SS, Hudson M, Fritzler MJ. Anti-centromere antibodies in a large cohort of systemic sclerosis patients: Comparison between immunofluorescence, CENP-A and CENP-B ELISA. Clin Chim Acta. 2011;412(2122):1937-1943. doi:10.1016/j.cca.2011.06.041

71. Hillen MR, Urso K, Koppe E, et al. Autoantigen TRIM21/Ro52 is expressed on the surface of antigen-presenting cells and its enhanced expression in Sjögren's syndrome is associated with B cell hyperactivity and type i interferon activity. RMD Open. 2020;6(2):15. doi:10.1136/rmdopen-2020-001184

72. Lee AYS. A review of the role and clinical utility of anti-Ro52/TRIM21 in systemic autoimmunity. Rheumatol Int. 2017;37(8):1323-1333. doi:10.1007/s00296-017-3718-1

73. Rhodes DA, Isenberg DA. TRIM21 and the Function of Antibodies inside Cells. Trends Immunol. 2017;38(12):916-926. doi:10.1016/j.it.2017.07.005

74. Oke V, Wahren-Herlenius M. The immunobiology of Ro52 (TRIM21) in autoimmunity: A critical review. J Autoimmun. 2012;39(1-2):77-82. doi:10.1016/j.jaut.2012.01.014

75. Ohlsson M, Jonsson R, Brokstad KA. Subcellular redistribution and surface exposure of the Ro52, Ro60 and La48 autoantigens during apoptosis in human ductal epithelial cells: A possible mechanism in the pathogenesis of Sjögren's syndrome. Scand J Immunol. 2002;56(5):456-469. doi:10.1046/j.1365-3083.2002.01072_79.x

76. Espinosa A, Hennig J, Ambrosi A, et al. Anti-Ro52 autoantibodies from patients with Sjögren's syndrome inhibit the Ro52 E3 ligase activity by blocking the E3/E2 interface. $J$ Biol Chem. 2011;286(42):36478-36491. doi:10.1074/jbc.M111.241786

77. Ben-Chetrit E. Target antigens of the SSA/Ro and SSB/La system. In: American Journal of Reproductive Immunology. Vol 28. Am J Reprod Immunol; 1992:256-258. doi:10.1111/j.1600-0897.1992.tb00809.x

78. van Woerkom JM, Geertzema JGN, Nikkels PGJ, Kruize AA, Smeenk RJT, Vroom TM. Expression of Ro/SS-A and La/SS-B determined by immunohistochemistry in healthy, inflamed and autoimmune diseased human tissues: A generalized phenomenon. Clin Exp Rheumatol. 2004;22(3):285-292.

79. Harley JB, Alexander EL, Bias WB, et al. Anti-Ro (SS-A) and Anti-La (SS-B) in patients with Sjögren's syndrome. Arthritis Rheum. 1986;29(2):196-206.

doi:10.1002/art.1780290207

80. Hoffmann S, Dumont M, Barra V, et al. CENP-A Is Dispensable for Mitotic Centromere Function after Initial Centromere/Kinetochore Assembly. Cell Rep. 2016;17(9):2394-2404. doi:10.1016/j.celrep.2016.10.084

81. Robitaille G, Christin MS, Clément I, Senécal JL, Raymond Y. Nuclear autoantigen CENP-B transactivation of the epidermal growth factor receptor via chemokine receptor 3 in vascular smooth muscle cells. Arthritis Rheum. 2009;60(9):2805-2816. doi:10.1002/art.24765

82. Robitaille G, Hénault J, Christin MS, Senécal JL, Raymond Y. The nuclear autoantigen CENP-B displays cytokine-like activities toward vascular smooth muscle cells. Arthritis Rheum. 2007;56(11):3814-3826. doi:10.1002/art.22972

83. Zian Z, Bennani Mechita M, Hamdouch K, et al. Proteomics characterization of CENP-B epitope in Moroccan scleroderma patients with anti-centromere autoantibodies. Immunol Lett. 2020;221:1-5. doi:10.1016/j.imlet.2020.02.005

84. Lee S, Hayashi H, Kumagai-Takei N, et al. Clinical evaluation of CENP-B and Scl-70 autoantibodies in silicosis patients. Exp Ther Med. 2017;13(6):2616-2622.

doi:10.3892/etm.2017.4331 
85. Onozuka Y, Shibata M, Yonezawa H, Terauti K, Miyachi K, Ueno Y. Clinical significance of anti-centromere antibody and anti-CENP-B antibody in sera of patients with primary biliary cirrhosis. Rinsho Byori. 1996;44(9):877-882. Accessed November 3, 2020. https://pubmed.ncbi.nlm.nih.gov/8911074/

86. Béland S, Vallin P, Désy O, Lévesque E, De Serres SA. Effects of alloantibodies to human leukocyte antigen on endothelial expression and serum levels of thrombomodulin. J Thromb Haemost. 2017;15(5):1020-1031. doi:10.1111/jth.13661

87. Valenzuela NM, Reed EF. Antibodies in Transplantation: The Effects of HLA and NonHLA Antibody Binding and Mechanisms of Injury. In: Methods in Molecular Biology (Clifton, N.J.). Vol 1034. NIH Public Access; 2013:41-70. doi:10.1007/978-1-62703-49372

88. Issa N, Cosio FG, Gloor JM, et al. Transplant glomerulopathy: Risk and prognosis related to anti-human leukocyte antigen class II antibody levels. Transplantation. 2008;86(5):681685. doi:10.1097/TP.0b013e3181837626

89. Chebotareva N, Bobkova I, Shilov E. Heat shock proteins and kidney disease: perspectives of HSP therapy. Cell Stress Chaperones. 2017;22(3):319-343. doi:10.1007/s12192-017-0790-0

90. Maehana T, Tanaka T, Kitamura H, et al. Heat shock protein $90 \alpha$ is a potential serological biomarker of acute rejection after renal transplantation. PLoS One. 2016;11(9). doi:10.1371/journal.pone.0162942

91. Liapis $H$, Romagnani $P$, Anders HJ. New insights into the pathology of podocyte loss: Mitotic catastrophe. Am J Pathol. 2013;183(5):1364-1374. doi:10.1016/j.ajpath.2013.06.033

92. Thomasova D, Anders HJ. Cell cycle control in the kidney. Nephrol Dial Transplant. 2015;30(10):1622-1630. doi:10.1093/ndt/gfu395

93. Tai $Y$, Wang $Q$, Korner H, Zhang L, Wei W. Molecular mechanisms of T cells activation by dendritic cells in autoimmune diseases. Front Pharmacol. 2018;9(JUN). doi:10.3389/fphar.2018.00642 


\section{SUPPLEMENTAL MATERIAL - TABLE OF CONTENTS}

Supplemental Table 1. List of non-HLA antigens studied in the protein array.

Supplemental Table 2. Pre-transplant antibodies against non-HLA antigens significantly altered between sexes.

Supplemental Table 3. Study of the association between IgG and IgM non-HLA antibody levels and relevant clinical and histological variables.

Supplemental Table 4. External validation of key non-HLA antibodies.

Supplemental Figure 1. Distribution of antibody levels according to patient sex.

Supplemental Figure 2. Clustering analysis of non-HLA antibodies significantly altered in AMR and mixed rejection.

Supplemental Figure 3. The evolution over time of 17 non-HLA antibodies increased in AMR and mixed rejection before transplant.

Supplemental Figure 4. The changes in the levels of relevant non-HLA antibodies over time, among patients who had both pre-transplant and at-diagnosis sera.

Supplemental Figure 5. The evolution over time of 11 non-HLA antibodies increased in AMR and mixed rejection after diagnosis. 


\section{FIGURE LEGENDS}

Figure 1. Experimental design and study workflow. In the discovery phase, we identified kidney transplant recipients with rejection diagnosed between 2008 and 2016 (A). Patient exclusion criteria were: 1) no serum sample available post-transplant; or 2) all serum samples collected within 21 days after PLEX and/or IVIG administration. Graft-age matched cases with acute tubular necrosis (ATN) were also included. A total of 166 sera were selected from 91 kidney transplant patients, with antibody-mediated rejection (AMR, n=43), 'mixed' antibody-mediated and cellular rejection ( $n=20)$, acute cellular rejection (ACR, $n=16)$, or ATN $(n=12)$. Our study workflow is shown in panel B. We first evaluated the MFI values of all the detected IgG and IgM, by comparing their distributions across different diagnoses. We then subjected all non-HLA antibodies to statistical analyses to assess differences between groups. We also performed clustering analyses to assess how the antibodies clustered in relation to the diagnoses and the anti-HLA DSA. Changes over time of key non-HLA antibodies were studied by plotting the MFI at diagnosis compared to MFI pre-transplant, in patients who had both samples available for the analysis. We next studied the association between the levels of each non-HLA antibody and the presence of histopathology lesions and/or anti-HLA DSA. We also interrogated our top antibodies of interest in an independent validation cohort. Finally, we built a protein-protein interaction network that integrates our top non-HLA antibody targets with our previous proteomics data sets of the AMR glomeruli and tubulointerstitium. DSA, donor-specific antibodies; Ig, immunoglobulin; MFI, median fluorescence intensity; PLEX, plasmapheresis; IVIG, intravenous immunoglobulin.

Figure 2. Distribution of antibody levels according to diagnosis. The density plots depict the distributions of IgG and IgM MFI values in AMR (orange), mixed rejection (purple), ACR (green), and ATN (teal) before transplant (A), at diagnosis (B), and post-diagnosis (C). In each patient, a value of zero was given to all antibodies with $M F I<200$. Log2-transformed MFI values were used to create the plots using ggplot2 3.3.2 in R. The x-axis encompasses the range of all MFI values among the detected antibodies, while the y-axis represents the frequency (density) of each of these values. AMR, antibody-mediated rejection; ACR, acute cellular rejection; ATN, acute tubular necrosis; Ig, immunoglobulin; MFI, median fluorescence intensity.

Figure 3. The evolution of top non-HLA antibodies increased in AMR and mixed rejection over time. The violin plots depict the distributions of the MFI values of the 6 antibodies significantly increased in AMR/mixed vs ACR (A) and the 3 antibodies significantly increased in 
AMR/Mixed vs ATN (B) at the time of diagnosis. Changes in the levels of these 9 antibodies over time were assessed by visualizing scatter plots of antibody MFI at diagnosis ( $y$-axis) versus antibody MFI before transplant (x-axis), in patients who had both serum samples (C). AMR, antibody-mediated rejection; ACR, acute cellular rejection; ATN, acute tubular necrosis; Ig, immunoglobulin; MFI, median fluorescence intensity.

Figure 4. Association between levels of non-HLA antibodies and relevant histologic and clinical parameters. The bubble plot represents an association matrix between the presence of histopathology and serology features important in AMR and the MFI values of non-HLA antibodies before transplant $(A)$ and at the time of diagnosis (B). The non-HLA antibodies that were more strongly associated with at least one clinical variable (according to p-value) are represented. The size of the nodes is inversely proportional to the $p$-value of the association. In turn, the color of the nodes indicates the direction of the association: increased antibody levels with the presence of histopathology lesions and/or presence of DSA are colored in red, while decreased antibody levels with the presence of histopathology lesions and/or presence of DSA are colored in beige. AMR, antibody-mediated rejection; ACR, acute cellular rejection; ATN, acute tubular necrosis; Ig, immunoglobulin; DSA, donor-specific antibodies; MFI, median fluorescence intensity.

Figure 5. External validation of non-HLA antibodies increased in AMR and mixed rejection at the time of diagnosis. Differences between groups in the levels of four antibodies that were significantly increased in AMR/Mixed rejection at the time of diagnosis in the discovery cohort (Toronto), and were significantly associated with the presence of microvascular lesions, were interrogated in an external cohort (Montreal) for validation. For each antibody, levels from kidney transplant patients with AMR/Mixed rejection were compared to the levels from patients with ACR or stable non-rejecting kidney grafts (Control) and plotted next to their corresponding levels in the Toronto cohort. Levels of IgG and IgM against Ro/SS-A(52 KDa) (A), PDH (B), La/SS-B (C), and CENP-B (D) are shown. Data are represented as median \pm interquartile range (IQR, box). ${ }^{*}<<0.05$ vs ACR or vs Control. AMR, antibody-mediated rejection; ACR, acute cellular rejection; MFI, median fluorescence intensity.

Figure 6. Network analysis of key antibody targets and proteins differentially expressed in kidney AMR. Physical protein-protein interactions of key non-HLA and HLA antibody targets were identified using the Integrated Interactions Database and visualized using NAViGaTOR 3.0.13. The selected targets were of relevance because their corresponding antibody was significantly 
increased in AMR/mixed patients at diagnosis, and/or significantly associated with the presence of AMR-related histopathology lesions or anti-HLA DSA. Turquoise and orange nodes represent the targets of non-HLA antibodies differentially increased in AMR/mixed patients compared to ACR and ATN, respectively. The nodes with purple highlight reflect targets of antibodies that were significantly associated with the presence of histopathology features and/or anti-HLA DSA. The gene names corresponding to the targets of antibodies validated in the external cohort (Montreal) are highlighted in turquoise. The nodes with a triangle shape represent targets of non-HLA antibodies increased in AMR/mixed rejection in both discovery and validation cohorts. The gene names of the non-HLA as well as HLA antibody targets that we previously found to be differentially expressed at the protein level in the AMR glomeruli or tubulointerstitium ${ }^{48}$ are colored in red. Purple edges connect proteins that are correlated to histopathological features, orange and turquoise edges connect proteins deregulated in AMR and mixed samples compared to ATN and ACR, respectively. Red edges connect proteins identified as deregulated in Clotet-Freixas et al., JASN, 2020. AMR, antibody-mediated rejection; ACR, acute cellular rejection; ATN, acute tubular necrosis.

\section{Figure 7. Summary of the key non-HLA antibodies associated with kidney AMR.}

Summary of relevant non-HLA antibodies increased in AMR/mixed rejection before transplant and at the time of diagnosis. IgG antibodies are depicted in green, while IgM antibodies are illustrated in red. The green ticks indicate that increased levels of IgG anti-Ro/SS-A(52KDa), IgG and IgM anti-CENP-B, and IgM anti-La/SS-B in AMR/Mixed rejection patients were validated in a second, independent cohort. ESKD, end-stage kidney disease; AMR, antibody-mediated rejection; Ig, immunoglobulin; DSA, donor-specific antibodies.

Figure S1. Distribution of antibody levels according to patient sex. The density plots depict the distributions of $\lg G$ and $\operatorname{lgM}$ MFI values before transplant in male (M, purple) and female (F, orange) patients. In each patient, a value of zero was given to all antibodies with $M F I<200$. Log2transformed MFI values were used to create the plots using ggplot2 3.3.2 in R. The $x$-axis encompasses the range of all MFI values among the detected antibodies, while the y-axis represents the frequency (density) of each of these values. AMR, antibody-mediated rejection; ACR, acute cellular rejection; ATN, acute tubular necrosis; Ig, immunoglobulin; MFI, median fluorescence intensity. 
Figure S2. Clustering analysis of non-HLA antibodies significantly altered in AMR and mixed rejection. The heatmaps illustrate the hierarchical clustering analyses of the non-HLA antibodies significantly differentially increased or decreased in AMR and mixed rejection before transplant $(A, B)$, at the time of diagnosis $(C, D)$, and post-transplant $(E, F)$, compared to $A C R$ or ATN $(P<0.05)$. Log2-transformed MFI values of each antibody were used to build the heatmaps. For each antibody, a value of zero was given to the samples with MFI $<200$ (below the limit of detection). Patient clustering was evaluated according to their diagnosis and the presence/absence of anti-HLA class-I and/or anti-HLA class-II DSA. AMR, antibody-mediated rejection; ACR, acute cellular rejection; ATN, acute tubular necrosis; Ig, immunoglobulin; DSA, donor-specific antibodies; MFI, median fluorescence intensity.

Figure S3. The evolution over time of 17 non-HLA antibodies increased in AMR and mixed rejection before transplant. The violin plots depict the distributions of the MFI values of 17 antibodies significantly altered before transplant in AMR/Mixed patients compared to ACR and/or ATN. AMR, antibody-mediated rejection; ACR, acute cellular rejection; ATN, acute tubular necrosis; Ig, immunoglobulin; MFI, median fluorescence intensity.

Figure S4. The changes in the levels of relevant non-HLA antibodies over time, among patients who had both pre-transplant and at-diagnosis sera. Changes over time in the levels of the $14 \mathrm{lgG}$ antibodies (A) and $11 \mathrm{lgM}$ antibodies (B) altered in AMR/mixed rejection before transplant and/or at the time of diagnosis were studied. Antibody fluctuations were assessed by visualizing antibody MFI at diagnosis (y-axis) versus antibody MFI before transplant (x-axis) using scatter dots. Overall, most antibodies did not appear to fluctuate in individuals over time. AMR, antibody-mediated rejection; Ig, immunoglobulin; MFI, median fluorescence intensity.

Figure S5. The evolution over time of 11 non-HLA antibodies increased in AMR and mixed rejection after diagnosis. The violin plots depict the distributions of the MFI values of 11 antibodies significantly altered after diagnosis in AMR/mixed patients compared to ACR and/or ATN. AMR, antibody-mediated rejection; ACR, acute cellular rejection; ATN, acute tubular necrosis; Ig, immunoglobulin; MFI, median fluorescence intensity. 
Table 1. Clinical parameters of the patient cohort. *Autoimmune conditions included: primary sclerosing cholangitis $(n=1)$, ANCA-vasculitis $(n=4), \operatorname{SLE}(n=2)$, and diabetes mellitus type I $(n=2)$. ESKD, end stage kidney disease; FSGS, focal and segmental glomerulosclerosis; IQR, interquartile range; PCKD, polycystic kidney disease; SLE, systemic lupus erythematosus; TMA, thrombotic microangiopathy

\begin{tabular}{|c|c|c|c|c|}
\hline & $\begin{array}{l}\text { Antibody mediated } \\
\text { rejection }\end{array}$ & Mixed rejection & $\begin{array}{l}\text { Acute cellular } \\
\text { rejection }\end{array}$ & $\begin{array}{c}\text { Acute tubular } \\
\text { necrosis }\end{array}$ \\
\hline Number of patients & 43 & 20 & 16 & 12 \\
\hline Sex - number of males, $n(\%)$ & $22(51)$ & $13(65)$ & $12(75)$ & $9(75)$ \\
\hline $\begin{array}{l}\text { Patient age at biopsy, median } \\
\text { years (IQR) }\end{array}$ & $50(39,58)$ & $48(36.7,56)$ & $44(36.2,51.5)$ & $64.5(62.2,69.7)$ \\
\hline $\begin{array}{l}\text { Time post-transplant, median } \\
\text { days (IQR) }\end{array}$ & $12(8,22)$ & $174(72,737)$ & $15.5(12,29.2)$ & $9.5(7.7,12.2)$ \\
\hline \multicolumn{5}{|l|}{ Cause of ESKD } \\
\hline Diabetic Nephropathy, n (\%) & $9(21)$ & $3(15)$ & $1(6.2)$ & 4 (33.3) \\
\hline IgA Nephropathy, n (\%) & $2(4.6)$ & $2(10)$ & $5(31.2)$ & $1(8.3)$ \\
\hline PCKD, n (\%) & $4(9.3)$ & $5(25)$ & $3(18.7)$ & $2(16.6)$ \\
\hline Vasculitis, n (\%) & $3(7)$ & $0(0)$ & $1(6.2)$ & $0(0)$ \\
\hline FSGS, n (\%) & $4(9.3)$ & $2(10)$ & $1(6.2)$ & $1(8.3)$ \\
\hline Reflux, n (\%) & $3(7)$ & $0(0)$ & $0(0)$ & $0(0)$ \\
\hline Hypertension, n (\%) & $3(7)$ & $1(5)$ & $0(0)$ & $1(8.3)$ \\
\hline SLE, n (\%) & $2(4.6)$ & $1(5)$ & $0(0)$ & $0(0)$ \\
\hline TMA, n (\%) & $2(4.6)$ & $0(0)$ & $0(0)$ & $0(0)$ \\
\hline Unknown, n (\%) & $3(7)$ & $4(20)$ & $0(0)$ & $2(16.6)$ \\
\hline Other, $\mathrm{n}(\%)$ & $8(18.6)$ & $3(15)$ & $5(31.2)$ & $1(8.3)$ \\
\hline $\begin{array}{l}\text { Pre-existing autoimmune } \\
\text { conditions }^{*}, \mathrm{n}(\%)\end{array}$ & $7(16.3)$ & $1(5)$ & $1(6.2)$ & $0(0)$ \\
\hline Renal replacement therapy & $40(93)$ & $16(80)$ & $14(87.5)$ & $12(100)$ \\
\hline Intermittent hemodialysis, $\mathrm{n}(\%)$ & $35(81.3)$ & $11(55)$ & $10(62.5)$ & $11(91.6)$ \\
\hline Peritoneal dialysis, $\mathrm{n}(\%)$ & $5(11.6)$ & $5(25)$ & $4(25)$ & $1(8.3)$ \\
\hline Preemptive, $\mathrm{n}(\%)$ & $3(7)$ & $4(20)$ & $2(12.5)$ & $0(0)$ \\
\hline Prior desensitization, n (\%) & $21(48.8)$ & $3(15)$ & $0(0)$ & $0(0)$ \\
\hline Eculizumab, $\mathrm{n}(\%)$ & $1(2.3)$ & $0(0)$ & $0(0)$ & $0(0)$ \\
\hline Rituximab, n (\%) & $3(7)$ & $2(10)$ & $0(0)$ & $0(0)$ \\
\hline \multicolumn{5}{|l|}{ Kidney transplant, donor type } \\
\hline Living donor, $\mathrm{n}(\%)$ & $21(49)$ & $9(45)$ & $9(56.2)$ & $3(25)$ \\
\hline Deceased donor, n (\%) & $22(51)$ & $11(55)$ & $7(43.7)$ & $9(75)$ \\
\hline \multicolumn{5}{|l|}{ Induction therapy } \\
\hline Thymoglobulin, $\mathrm{n}(\%)$ & $38(88.3)$ & $16(80)$ & $11(68.8)$ & $12(100)$ \\
\hline Basiliximab, n (\%) & $3(7)$ & $3(15)$ & $5(31.2)$ & $0(0)$ \\
\hline Unknown, n (\%) & $2(4.6)$ & $1(5)$ & $0(0)$ & $0(0)$ \\
\hline \multicolumn{5}{|l|}{$\begin{array}{l}\text { Maintenance therapy, number } \\
(\%)\end{array}$} \\
\hline Prednisone & $43(100)$ & $20(100)$ & $16(100)$ & $12(100)$ \\
\hline Anti-proliferative & $42(97.6)$ & $20(100)$ & $16(100)$ & $12(100)$ \\
\hline Calcineurin Inhibitor & $43(100)$ & $20(100)$ & $16(100)$ & $12(100)$ \\
\hline ABO incompatible, $n(\%)$ & $5(11.6)$ & $0(0)$ & $0(0)$ & $0(0)$ \\
\hline Delayed graft function, $\mathrm{n}(\%)$ & $17(39.5)$ & $3(15)$ & $4(25)$ & $2(16.6)$ \\
\hline Primary non-function, $\mathrm{n}(\%)$ & $2(4.6)$ & $1(5)$ & $0(0)$ & $0(0)$ \\
\hline \multicolumn{5}{|l|}{ DSA, current or historic } \\
\hline Any DSA & $37(86)$ & $16(80)$ & $0(0)$ & $4(33.3)$ \\
\hline Class I, n (\%) & $23(53.4)$ & $7(35)$ & $0(0)$ & $4(33.3)$ \\
\hline Class II, n (\%) & $31(72)$ & $16(80)$ & $0(0)$ & $0(0)$ \\
\hline Unknown, n (\%) & $2(4.6)$ & $1(5)$ & $1(6.2)$ & $1(8.3)$ \\
\hline
\end{tabular}


bioRxiv preprint doi: https://doi.org/10.1101/2020.12.02.408922; this version posted December 2, 2020. The copyright holder for this preprint (which was not certified by peer review) is the author/funder, who has granted bioRxiv a license to display the preprint in perpetuity. It is made

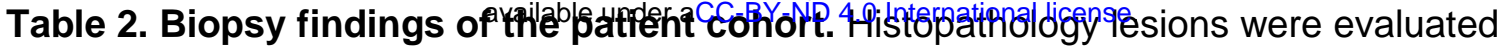
according to the most updated Banff classification. IQR, interquartile range; ah, arteriolar hyalinosis; c4d, c4 deposition; cg, chronic glomerulopathy; ci, interstitial fibrosis; ct, tubular atrophy; cv, vascular fibrous intimal thickening; g, glomerulitis; i, interstitial inflammation; $\mathrm{mm}$, mesangial matrix expansion; ptc, peritubular capillaritis; ti, total inflammation; t, tubulitis; $\mathrm{v}$, intimal arteritis.

\begin{tabular}{|c|c|c|c|c|}
\hline Median (IQR) & AMR (43) & MIXED (20) & ACR (16) & ATN (12) \\
\hline $\mathbf{i}$ & $0(0,0)$ & $2(1.7,3)$ & $2(1.7,2)$ & $0(0,0)$ \\
\hline $\mathbf{t}$ & $0(0,0)$ & $2(2,3)$ & $3(2.7,3)$ & $0(0,0)$ \\
\hline $\mathbf{t i}$ & $0(0,1)$ & $2(2,3)$ & $2(2,3)$ & $0(0,0)$ \\
\hline $\mathbf{g}$ & $2(0,2)$ & $0(0,2)$ & $0(0,0)$ & $0(0,0)$ \\
\hline $\mathbf{p t c}$ & $1(0,2)$ & $2(1,2)$ & $1(0,1)$ & $0(0,0)$ \\
\hline $\mathbf{c g}$ & $0(0,0)$ & $0(0,0)$ & $0(0,0)$ & $0(0,0)$ \\
\hline $\mathbf{m m}$ & $0(0,0)$ & $0(0,0)$ & $0(0,0)$ & $0(0,0)$ \\
\hline $\mathbf{v}$ & $0(0,0)$ & $1(0,1)$ & $0(0,0)$ & $0(0,0)$ \\
\hline $\mathbf{c i}$ & $0(0,0)$ & $1(0,1)$ & $1(0,1)$ & $0(0,0)$ \\
\hline $\mathbf{c t}$ & $0(0,0)$ & $1(0,1)$ & $1(0.7,1)$ & $0(0,1)$ \\
\hline $\mathbf{a h}$ & $0(0,1)$ & $1(0,1)$ & $0(0,1)$ & $0(0,0)$ \\
\hline $\mathbf{c v}$ & $0(0,1)$ & $1(0,1.5)$ & $1(0,1.7)$ & $1(0,1)$ \\
\hline $\mathbf{C 4 d}$ & $3(3,3)$ & $3(2,3)$ & $0(0,0)$ & $0(0,0)$ \\
\hline Globally sclerosed glomeruli, \% (IQR) & $4(0,7)$ & $5(0,11.7)$ & $4(0,11.5)$ & $4(0,8.2)$ \\
\hline
\end{tabular}


Table 3. Antibodies against non-HLA antigens significantly altered in AMR/Mixed rejection, compared to ACR and/or ATN. Significantly altered ( $P$ value < 0.05) $\lg \mathrm{G}$ and $\operatorname{lgM}$ antibodies before transplant, at diagnosis, and post-diagnosis are shown. Ig, immunoglobulin; AMR, antibody-mediated rejection; ACR, acute cellular rejection; ATN, acute tubular necrosis; SEM, standard error of the median; B, bovine; R, recombinant; NR, non-recombinant; hp, high purity.

\begin{tabular}{|c|c|c|c|c|c|}
\hline \multirow{3}{*}{ Antibody class } & \multirow{3}{*}{ Antibody name } & \multirow{3}{*}{ Antigen specificity } & \multicolumn{3}{|c|}{ Antibody levels } \\
\hline & & & \multicolumn{3}{|c|}{ BEFORE TRANSPLANT } \\
\hline & & & AMR/MIXED (Median \pm SEM) & ACR (Median \pm SEM) & $P$ value \\
\hline $\lg G$ & $\lg G$ M2 & $\begin{array}{l}\text { M2 (PDC-E2 + OGDC-E2 } \\
\text { + BCOADC-E2) }\end{array}$ & $267.0 \pm 143.6$ & $0 \pm 105.6$ & 0.0051 \\
\hline $\lg G$ & IgG CENP-B & $\begin{array}{c}\text { Major centromere } \\
\text { autoantigen B }\end{array}$ & $312.5 \pm 144.2$ & $0 \pm 223.5$ & 0.0097 \\
\hline $\lg G$ & IgG Ro / SS-A (52 KDa) & Ro / SS-A (52 KDa) & $315.0 \pm 1732.5$ & $0 \pm 98.3$ & 0.0112 \\
\hline $\lg G$ & IgG Gliadin & Gliadin & $3209.0 \pm 961.8$ & $1618.5 \pm 495.8$ & 0.0157 \\
\hline $\lg G$ & IgG Desmin & Desmin & $0.0 \pm 207.0$ & $0 \pm 125.9$ & 0.0223 \\
\hline $\lg G$ & IgG PDH & Pyruvate dehydrogenase & $238.0 \pm 103.5$ & $0 \pm 87.4$ & 0.0232 \\
\hline $\lg G$ & $\operatorname{lgG}$ SmD3 & Sm D3 & $0 \pm 21.8$ & $0 \pm 0$ & 0.0368 \\
\hline $\lg G$ & IgG smooth muscle & Smooth muscle actin & $382.5 \pm 40.5$ & $310.7 \pm 52.2$ & 0.0457 \\
\hline \multirow[t]{2}{*}{$\lg G$} & $\operatorname{lgG}$ Jo-1 & His-tRNA Synthase & $0 \pm 81.2$ & $0 \pm 34.9$ & 0.0471 \\
\hline & & & AMR/MIXED (Median \pm SEM) & ATN (Median \pm SEM) & $P$ value \\
\hline $\lg M$ & $\operatorname{lgM}$ PL-12 & Alanyl-tRNA synthetase & $1049.5 \pm 232.7$ & $352.0 \pm 390.6$ & 0.0074 \\
\hline $\lg M$ & IgM HGMEC Lysate & $\begin{array}{l}\text { Glomerular endothelial } \\
\text { cells }\end{array}$ & $1393.5 \pm 265.3$ & $752 \pm 244.7$ & 0.0224 \\
\hline $\lg M$ & IgM PM / Scl 100 & PM / Scl-100 & $317.5 \pm 65.8$ & $0 \pm 38.1$ & 0.0234 \\
\hline $\lg M$ & IgM OGDC-E2 & M2 (OGDC) & $426 \pm 200.2$ & $0 \pm 81.1$ & 0.0298 \\
\hline $\lg G$ & IgG HCEC Cytoplasm & Cardiac endothelial cells & $380.5 \pm 54.7$ & $222 \pm 124.9$ & 0.0309 \\
\hline $\begin{array}{l}\text { bioRxiv preprint doi: htt } \\
\text { which wakglblt certified }\end{array}$ & $\begin{array}{r}\text { ss://doi.org/10.1101/2020.12.02.40 } \\
\text { by peer revidgMMstteG3uthor/funde } \\
\text { available under }\end{array}$ & 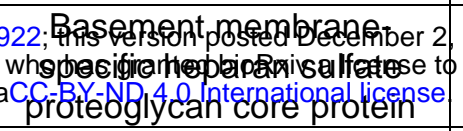 & $\begin{array}{l}\text { 2020. The copyright holder for this preprit } \\
\text { display the }\end{array}$ & $0 \pm 54.1$ & 0.0365 \\
\hline $\lg M$ & $\operatorname{lgM}$ LKM $1 \mathrm{hp}$ & $\begin{array}{l}\text { LKM } 1 \text { hp antigen of } \\
\text { Cytochrome P450 2D6 }\end{array}$ & $210.5 \pm 42.2$ & $0 \pm 878.7$ & 0.0393 \\
\hline $\lg G$ & $\begin{array}{c}\text { IgG Ro / SS-A (60KDa, } \\
\text { R) }\end{array}$ & Ro / SS-A (60 KDa) & $0 \pm 59.2$ & $296 \pm 79.1$ & 0.0403 \\
\hline $\lg M$ & $\lg M \operatorname{Sm}(N R, B)$ & $\begin{array}{l}\text { Small nuclear } \\
\text { ribonucleoprotein Sm }\end{array}$ & $311 \pm 62.3$ & $0 \pm 274.7$ & 0.0470 \\
\hline $\lg G$ & $\lg G$ tTG & Tissue Transglutaminase & $0 \pm 36.0$ & $0 \pm 192.7$ & 0.0484 \\
\hline $\lg G$ & IgG PDH & Pyruvate dehydrogenase & $238 \pm 103.6$ & $0 \pm 192.7$ & 0.0494 \\
\hline \multirow{3}{*}{ Antibody class } & \multirow{3}{*}{ Antibody name } & \multirow{3}{*}{ Antigen specificity } & \multicolumn{3}{|c|}{ Antibody levels } \\
\hline & & & \multicolumn{3}{|c|}{ AT DIAGNOSIS } \\
\hline & & & AMR/MIXED (Median \pm SEM) & ACR (Median \pm SEM) & $P$ value \\
\hline $\lg G$ & $\operatorname{lgG}$ CENP-B & $\begin{array}{c}\text { Major centromere } \\
\text { autoantigen } \mathrm{B}\end{array}$ & $510.0 \pm 159.3$ & $0 \pm 59.1$ & 0.0126 \\
\hline $\lg G$ & IgG Ro / SS-A (52 KDa) & Ro / SS-A (52 KDa) & $353.5 \pm 2301.6$ & $0 \pm 191.8$ & 0.0325 \\
\hline $\lg M$ & $\operatorname{lgM~La~/~SS-B~}$ & La / SS-B & $735.5 \pm 479.1$ & $296.0 \pm 104.6$ & 0.0261 \\
\hline $\lg M$ & IgM Ribo P1 & $\begin{array}{c}\text { Ribosomal } \\
\text { Phosphoprotein P1 }\end{array}$ & $0 \pm 86.7$ & $0 \pm 0$ & 0.0284 \\
\hline $\lg M$ & IgM CENP-B & $\begin{array}{l}\text { Major centromere } \\
\text { autoantigen B }\end{array}$ & $666.5 \pm 260.1$ & $262.0 \pm 112.7$ & 0.0447 \\
\hline $\lg M$ & IgM PDH & PDH & $251.0 \pm 130.9$ & $0 \pm 55.8$ & 0.0472 \\
\hline & & & AMR/MIXED (Median \pm SEM) & ATN (Median \pm SEM) & $P$ value \\
\hline $\lg G$ & $\lg G$ M2 & $\begin{array}{l}\text { M2 (PDC-E2 + OGDC-E2 } \\
\text { + BCOADC-E2) }\end{array}$ & $219 \pm 202.0$ & $0 \pm 0$ & 0.0313 \\
\hline $\lg G$ & $\lg G \mathrm{Sm}(\mathrm{NR}, \mathrm{B})$ & Bovine Sm proteins & $0 \pm 179.0$ & $0 \pm 0$ & 0.0416 \\
\hline $\lg G$ & $\lg G$ Human $\lg A$ & Human $\lg \mathrm{A}$ & $750.5 \pm 643.1$ & $0 \pm 226.4$ & 0.0495 \\
\hline \multirow{3}{*}{ Antibody class } & \multirow{3}{*}{ Antibody name } & \multirow{3}{*}{ Antigen specificity } & \multicolumn{3}{|c|}{ Antibody levels } \\
\hline & & & \multicolumn{3}{|c|}{ POST-DIAGNOSIS } \\
\hline & & & AMR/MIXED (Median \pm SEM) & ACR (Median \pm SEM) & $P$ value \\
\hline $\lg G$ & IgG Beta 2-Glyc & $\beta 2$-Glycoprotein 1 & $0 \pm 12.7$ & $0 \pm 70.6$ & 0.0033 \\
\hline $\lg G$ & $\operatorname{lgG}$ TPO & Thyroid peroxidase & $0 \pm 80.4$ & $357 \pm 394.2$ & 0.0128 \\
\hline $\lg G$ & $\lg \mathrm{t}$ tTG & Tissue Transglutaminase & $0 \pm 22.3$ & $0 \pm 71.3$ & 0.0234 \\
\hline $\lg G$ & IgG Tropomyosin & Tropomyosin & $234 \pm 101.6$ & $380.75 \pm 366.3$ & 0.0431 \\
\hline $\lg G$ & IgG Gliadin & Gliadin & $2306 \pm 917.0$ & $1081.25 \pm 812.7$ & 0.0446 \\
\hline \multirow[t]{2}{*}{$\lg G$} & $\lg G$ human $\lg G F(a b) 2$ & $\begin{array}{c}\mathrm{F}(\mathrm{ab}) 2 \text { fragment of Human } \\
\operatorname{lgG}\end{array}$ & $8029 \pm 2413.3$ & $3101.75 \pm 2826.0$ & 0.0475 \\
\hline & & & AMR/MIXED (Median \pm SEM) & ATN (Median \pm SEM) & $P$ value \\
\hline $\lg G$ & IgG alphaB-crystallin & Alpha-crystallin B chain & $0 \pm 502.5$ & $693.5 \pm 370.6$ & 0.0060 \\
\hline $\lg G$ & IgG Troponin I & Troponin I & 272.5 & $0 \pm 0$ & 0.0208 \\
\hline $\lg G$ & IgG Grp78/BiP & $\begin{array}{c}\text { Heat shock } 70 \text { kDa protein } \\
5\end{array}$ & $303.0 \pm 106.0$ & $811.5 \pm 262.9$ & 0.0336 \\
\hline $\lg G$ & IgG Thyrogobulin & Thyroglobulin & $212.5 \pm 36.4$ & $0 \pm 0$ & 0.0378 \\
\hline $\lg G$ & IgG dsDNA (plasmid) & dsDNA & $206.5 \pm 100.1$ & $0 \pm 0$ & 0.0378 \\
\hline $\lg M$ & $\operatorname{lgM}$ ADRB2 & Beta-2 adrenergic receptor & $265 \pm 79.8$ & $0 \pm 57.1$ & 0.0423 \\
\hline
\end{tabular}



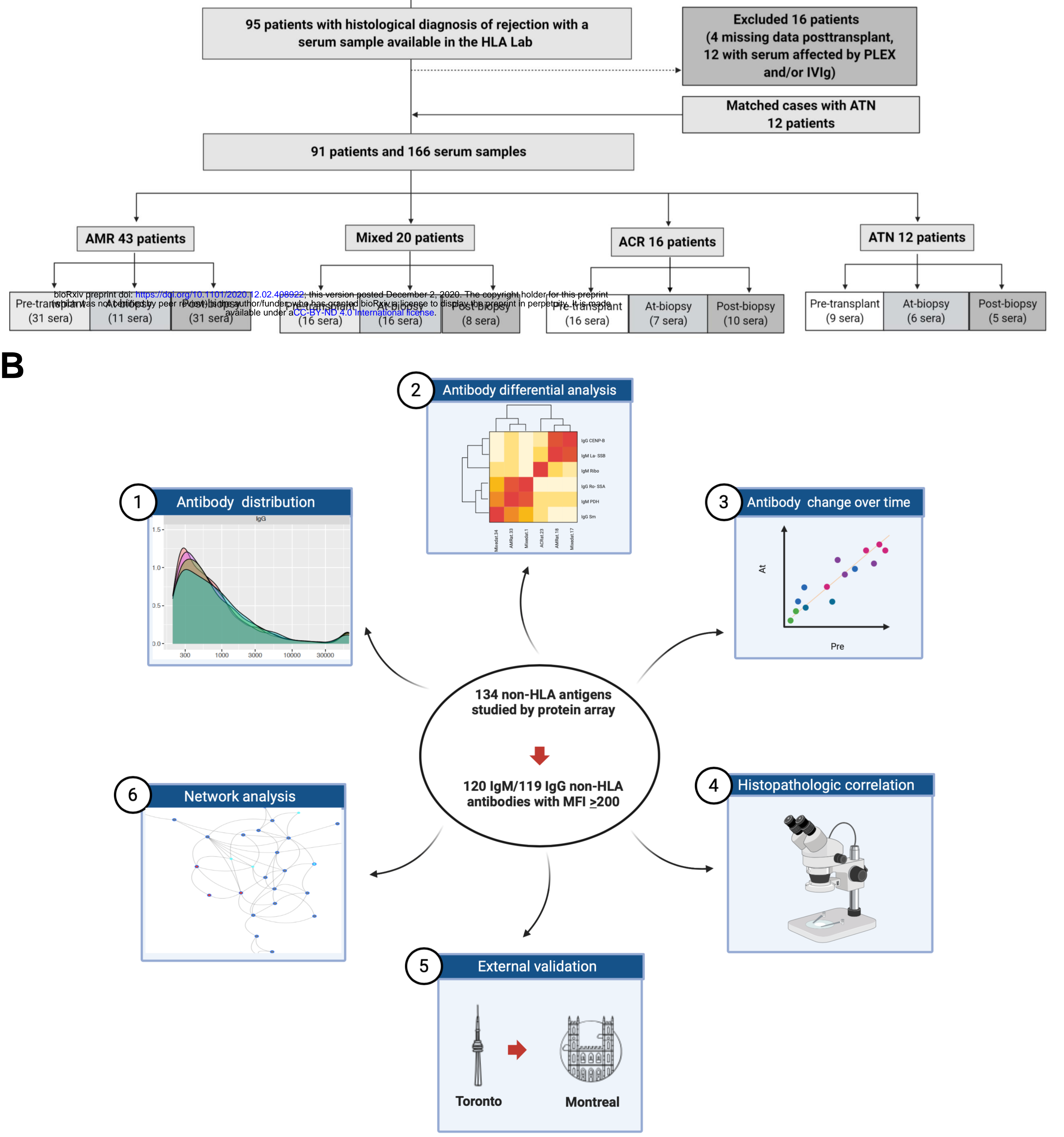
A

Diagnosis

AMR

MIXED

$A C R$

Antibody distribution pre-transplant

$\lg G$

$1.5-$

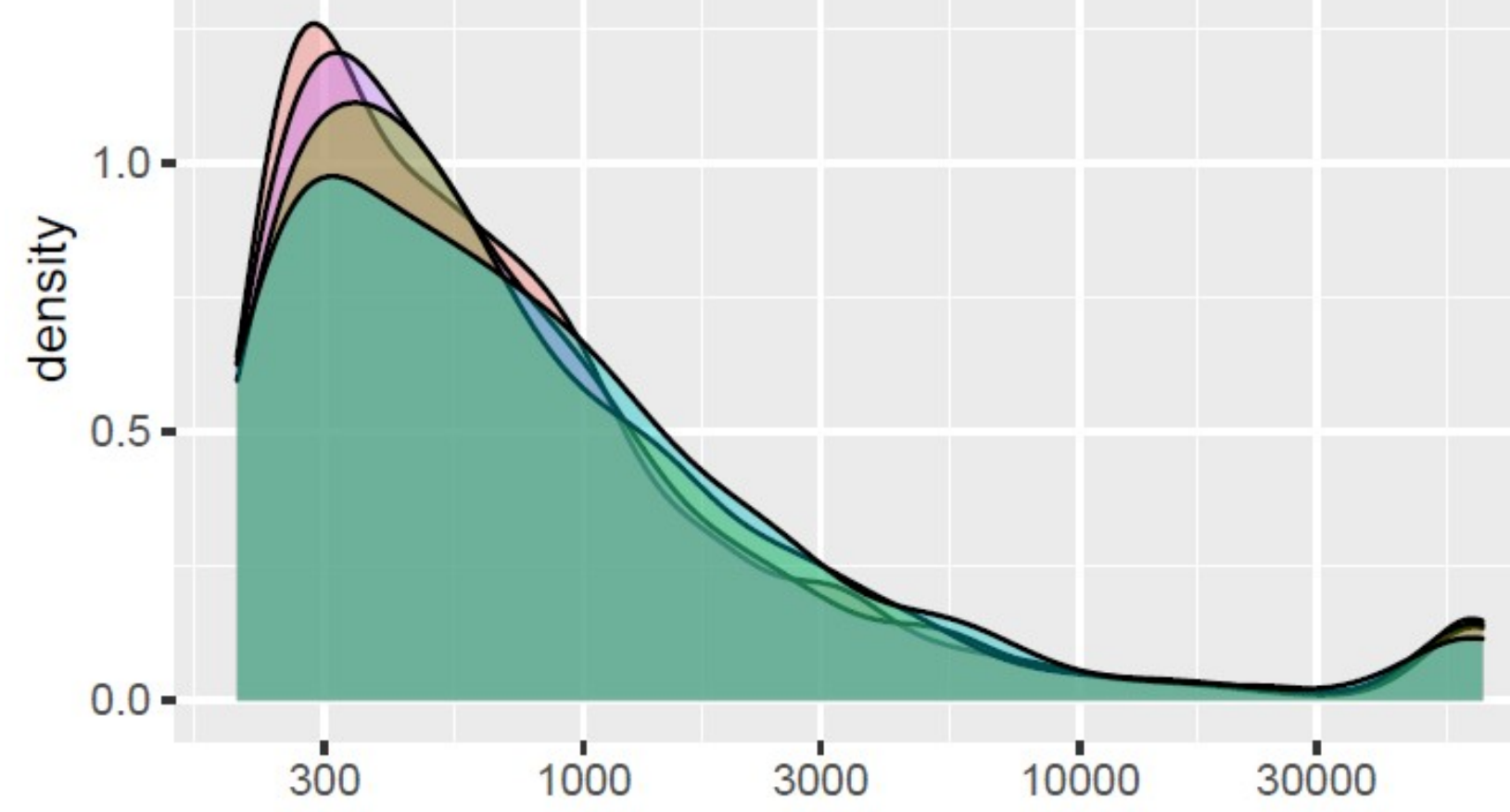

B

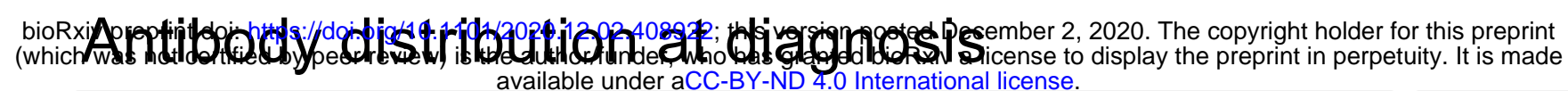

$\lg G$

$1.5-$

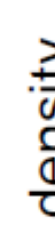

$0.0-$

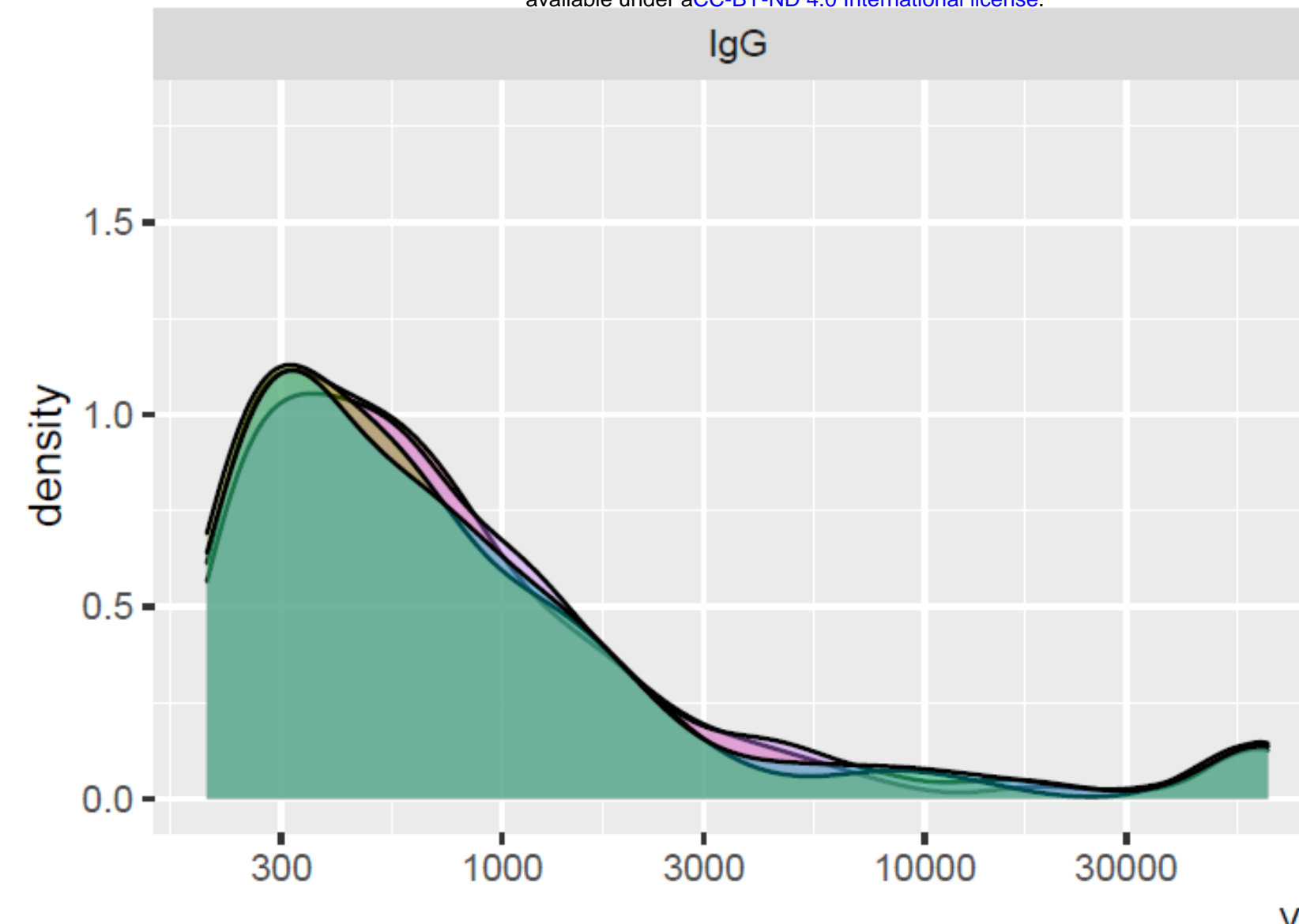

value $\lg \mathrm{M}$

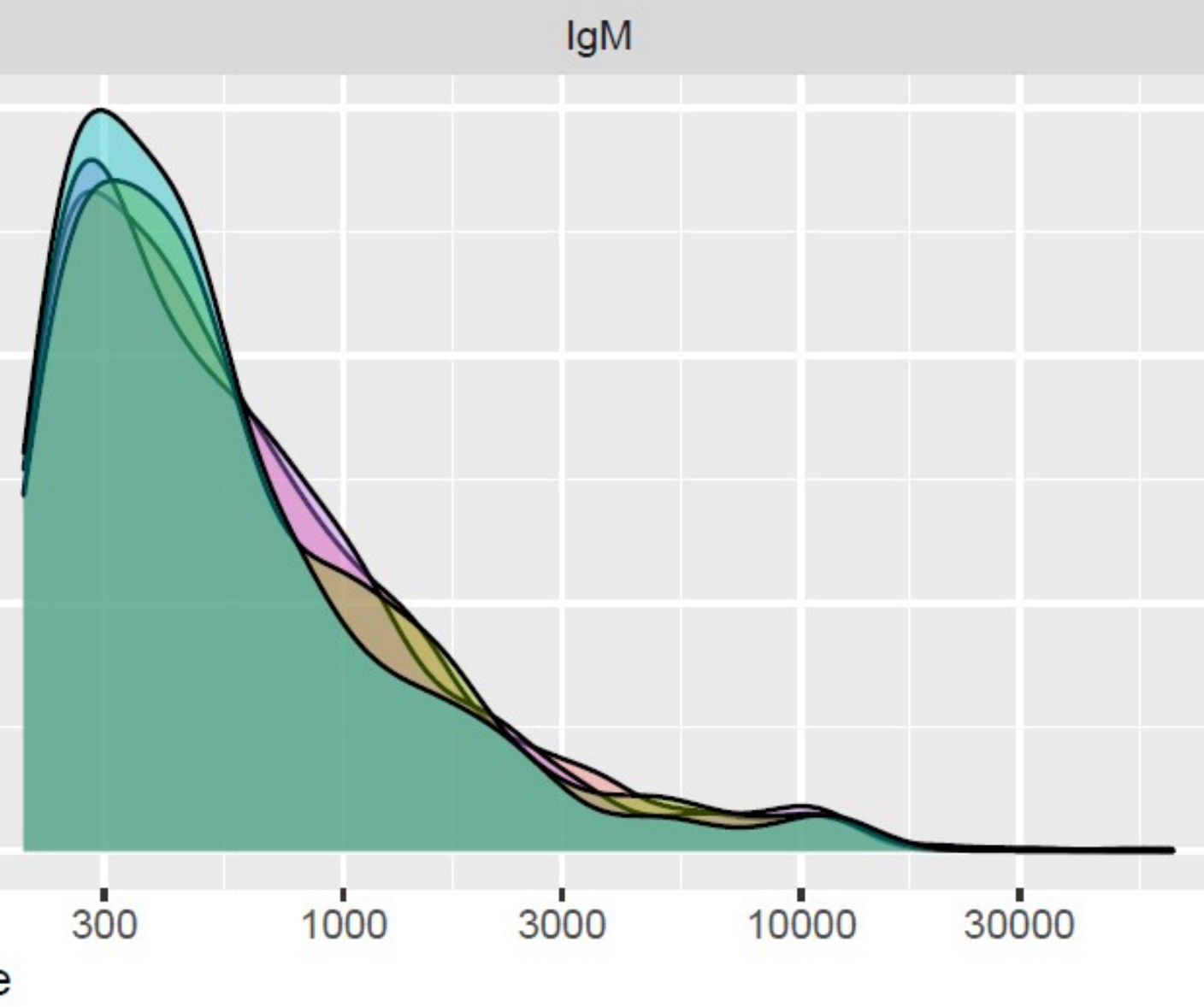

value

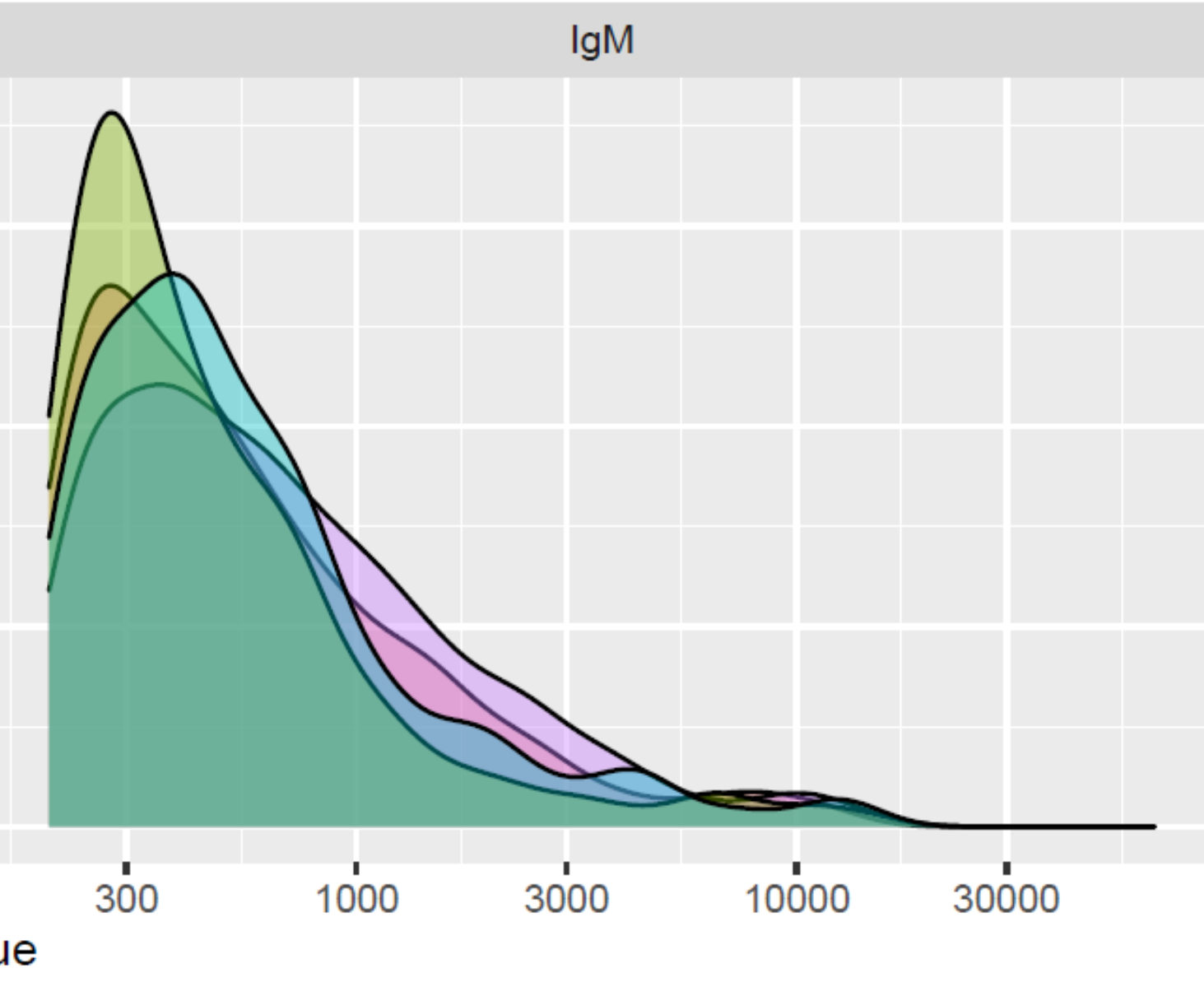

C

Antibody distribution post-diagnosis
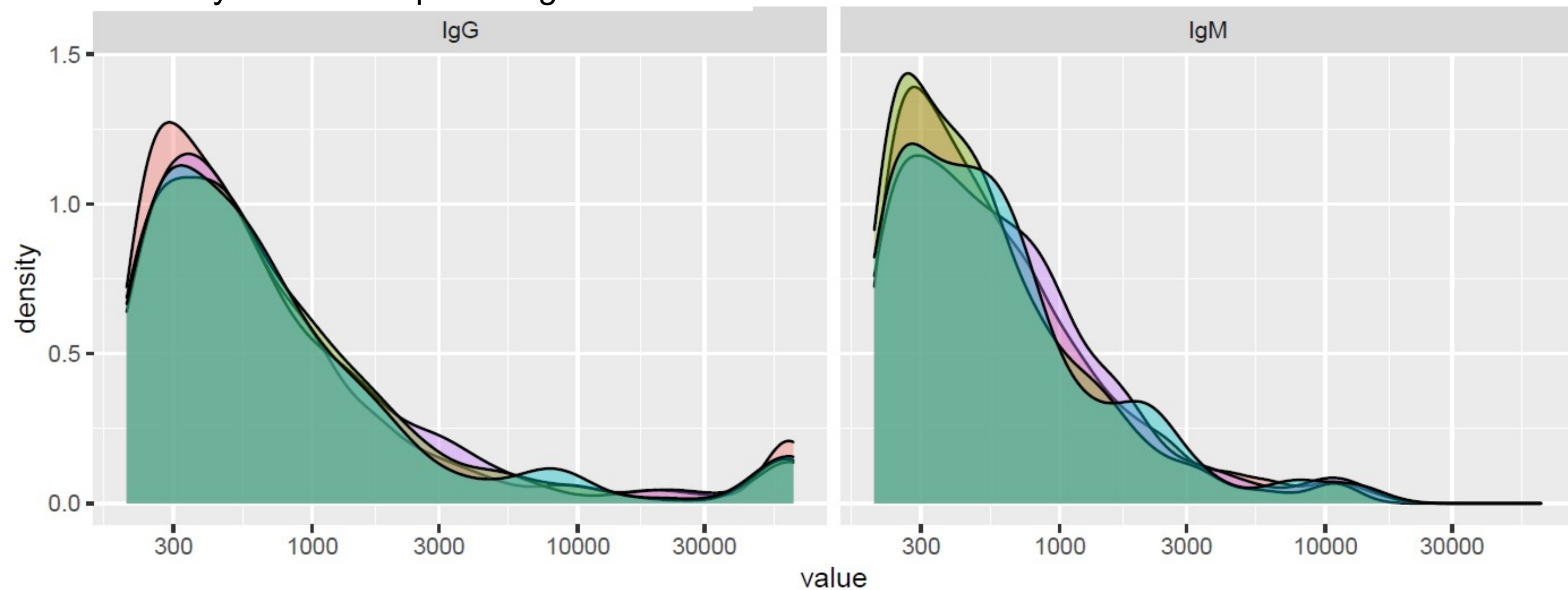

value 
Figure 4

Vascular fibrous intimal thickening tal inflammation Peritubular

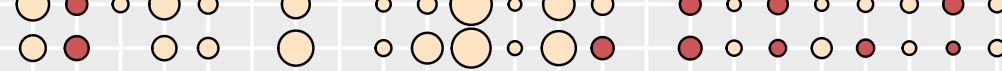
0000000000000000000000

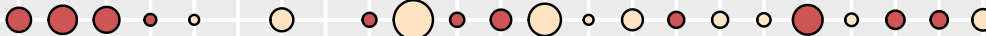

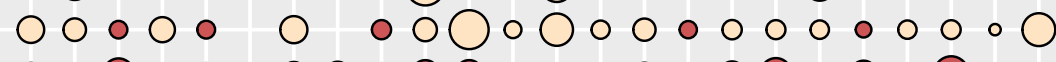
timal arteritis inflammation Glomerulitis glomerulopathy - O C4 deposition Anti-HLA DSA Anti-HLA class II Anti-HLA class I.
DSA .0000 .8 00000000000000000000000

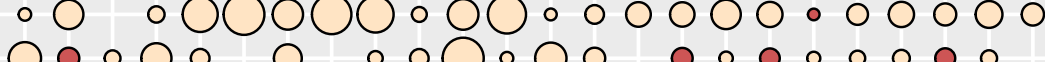

Vascular fibrous intimal thickening Tubulitis Peritubula capillaritis Intimal arteritis inflammation Glomerulitis 00000000000000000 00000000000000000 ○ $0 \circ 0000000000000$ 00000000000000000

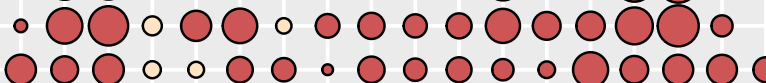
glomerulopathy Anti-HLA DSA Anti-HLA class II Anti-HLA class I $\bigcirc 000000$

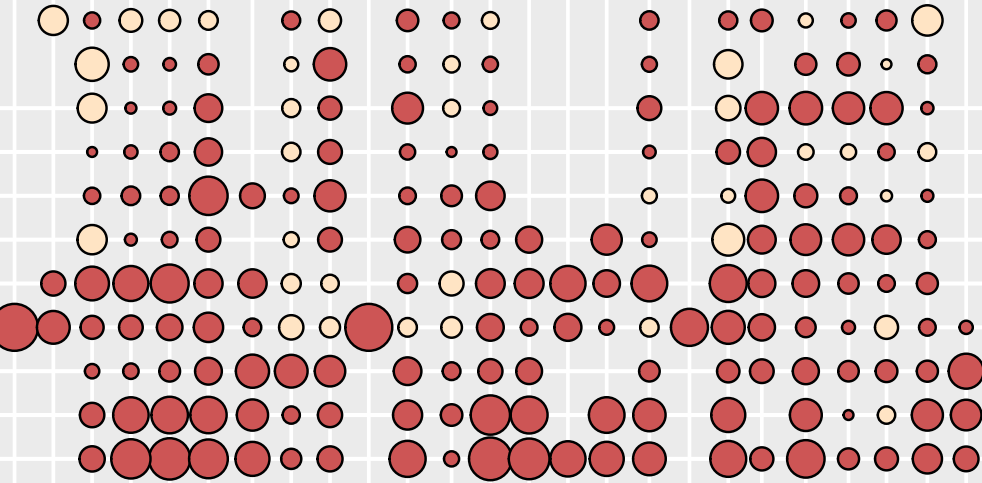

0

0

1000008 $\begin{array}{lllllllllllllll}0 & 0 & 0 & 0 & 0 & 0\end{array}$

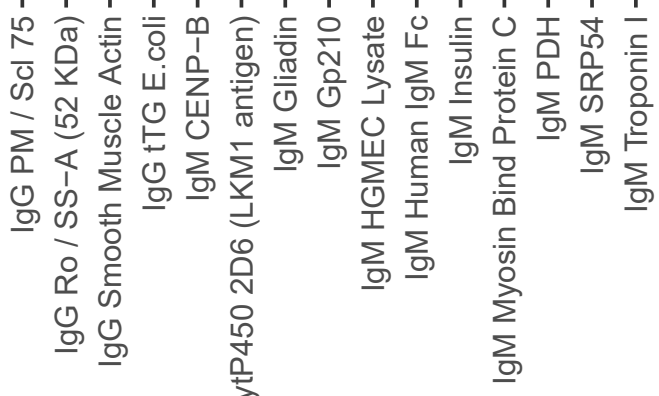

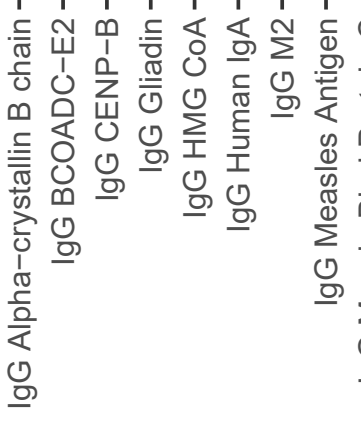

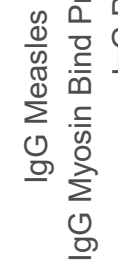

$-\log (p-$ value $) \circ 0$ 

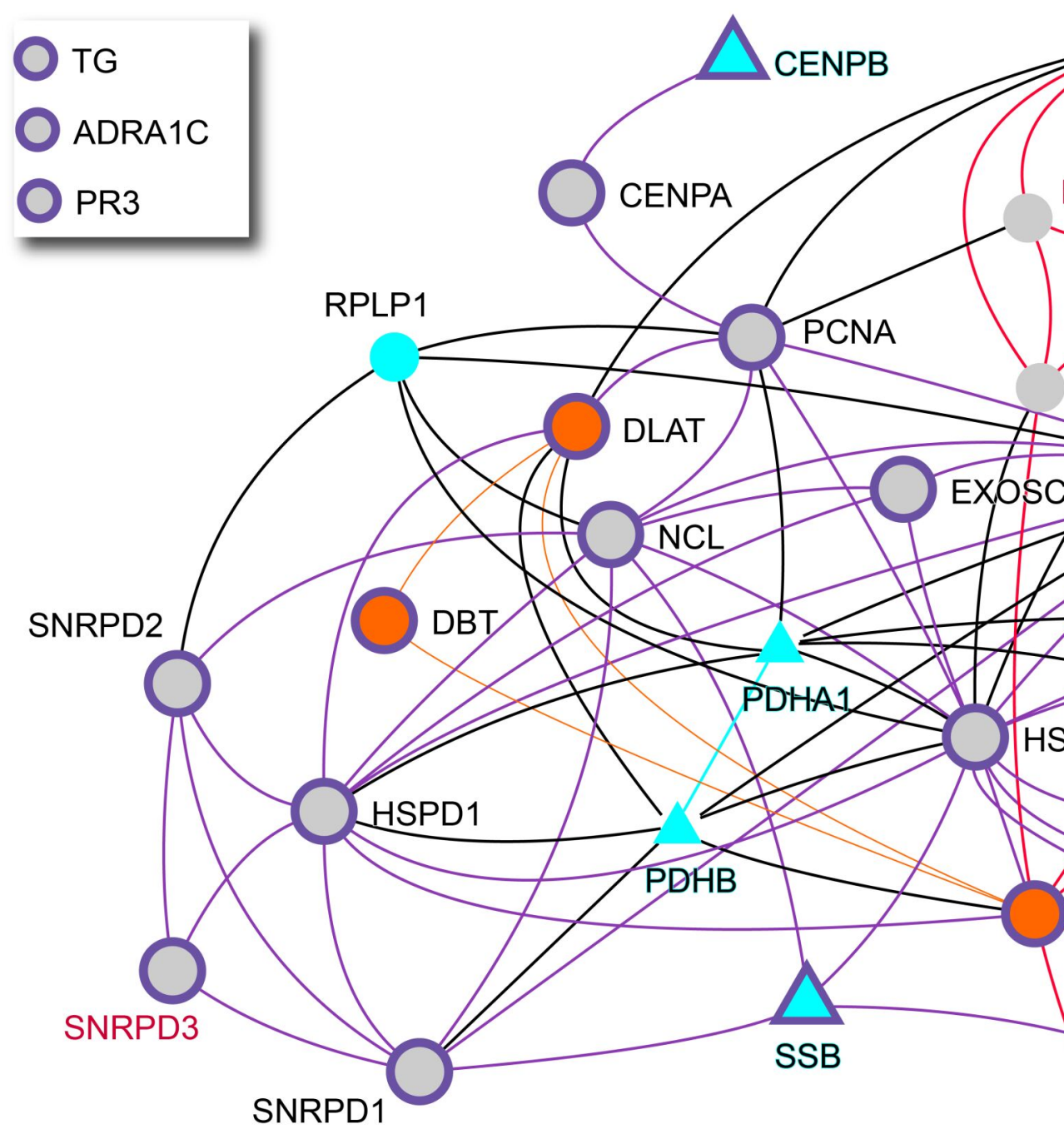

Correlation to histopathological features

- AMR and Mixed vs ACR

- AMR and Mixed vs ATN

Clotet-Freixas et al. 2020

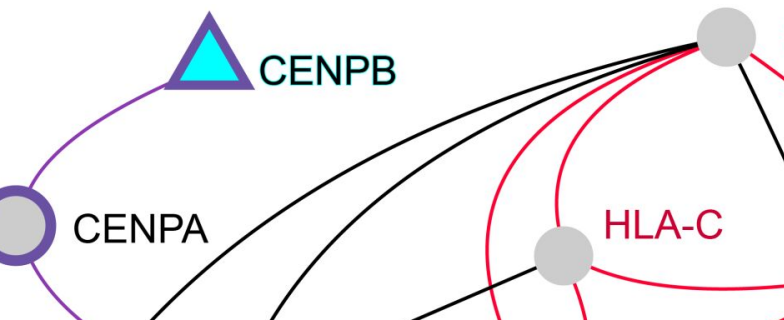

HLA-B

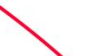

Increased in AMR \& Mixed cases (Toronto \& Montreal) 


\section{Kidney Transplant}

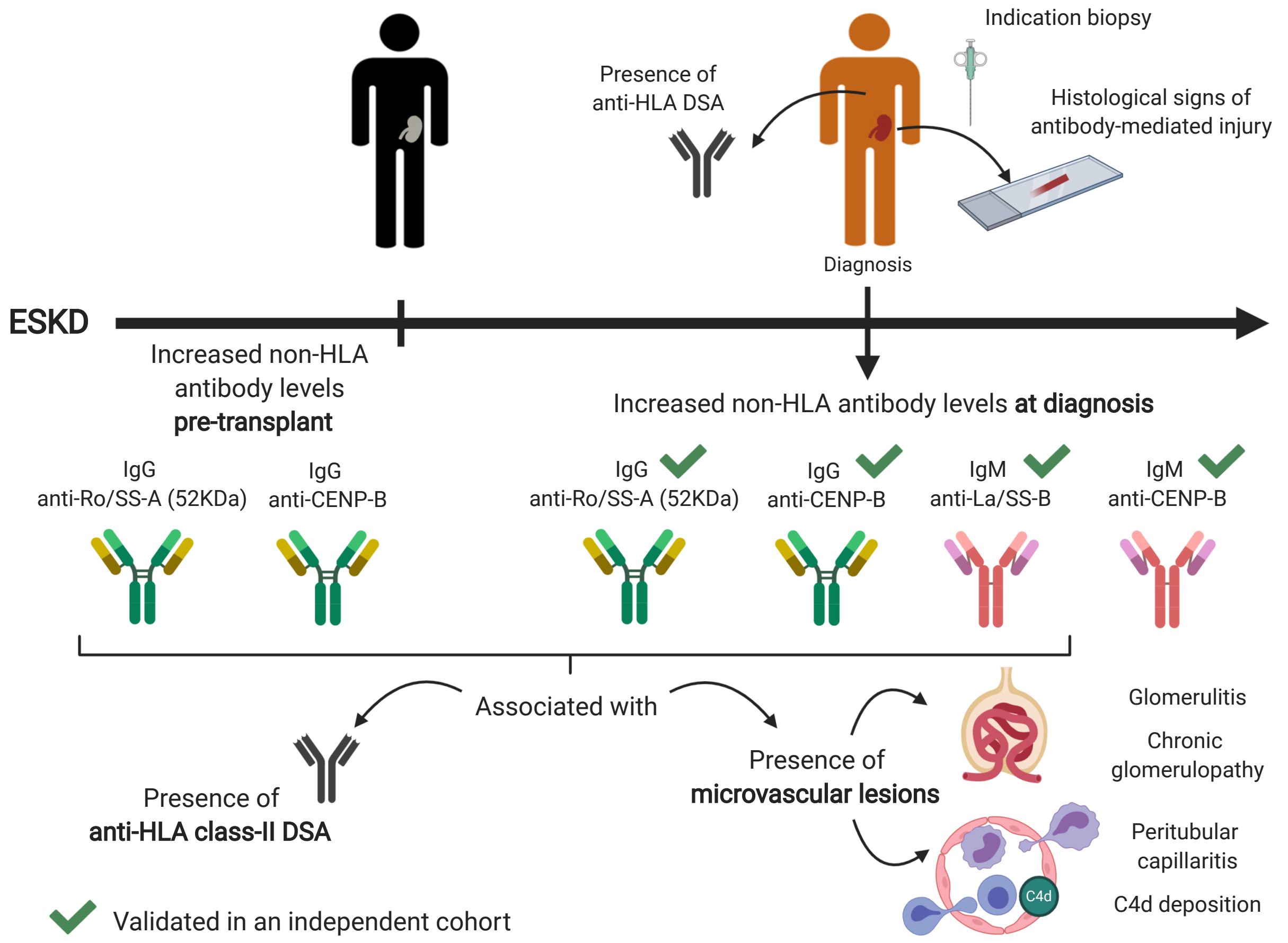

\section{AMR/Mixed rejection}

Figure 7 


\section{Antibody distribution per sex (pre-transplant levels)}

Figure S1

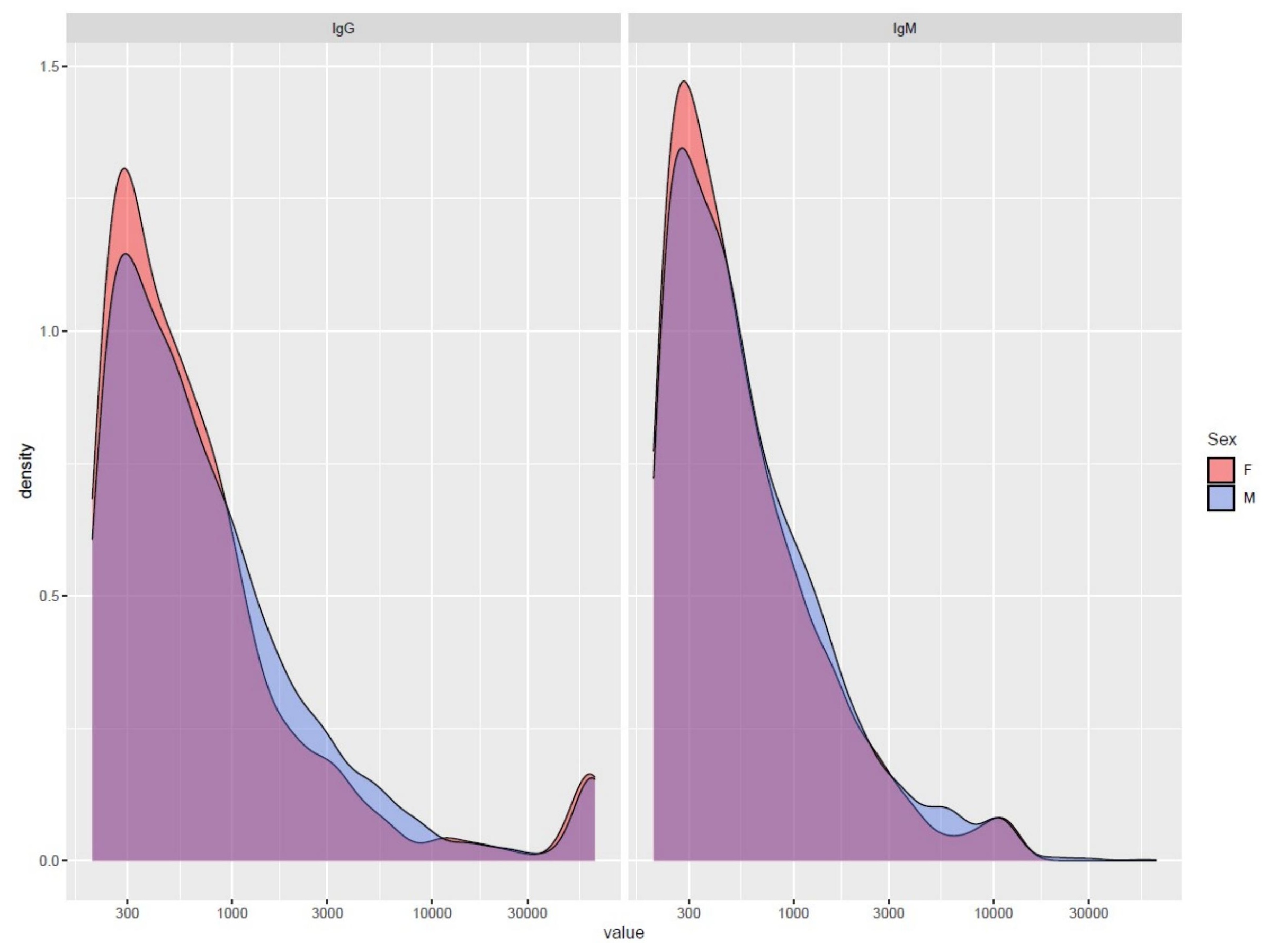




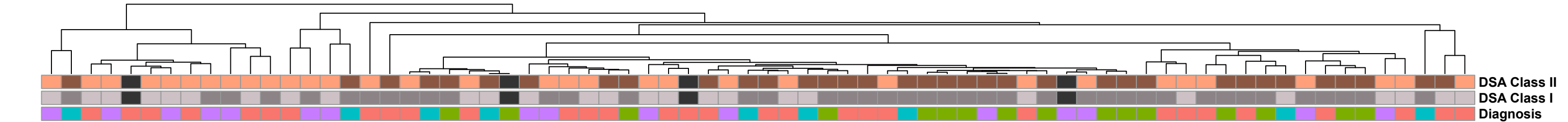

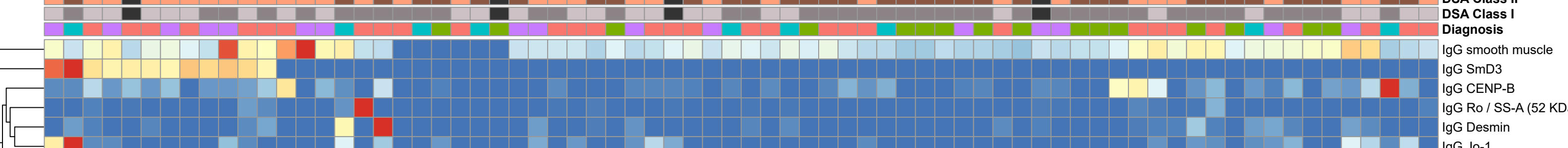

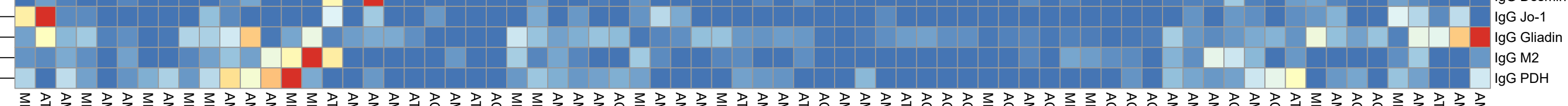

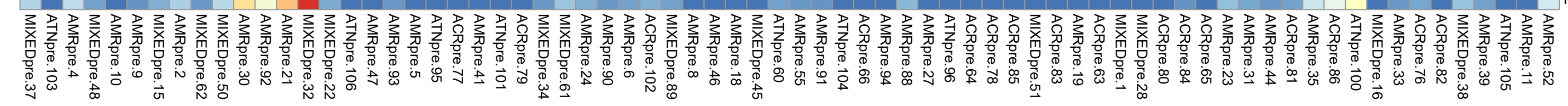

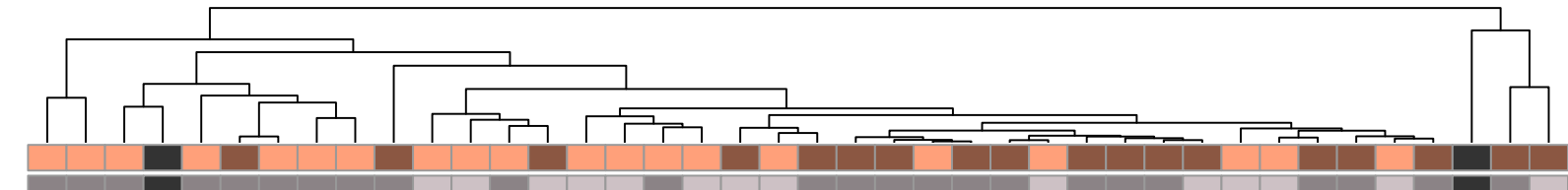

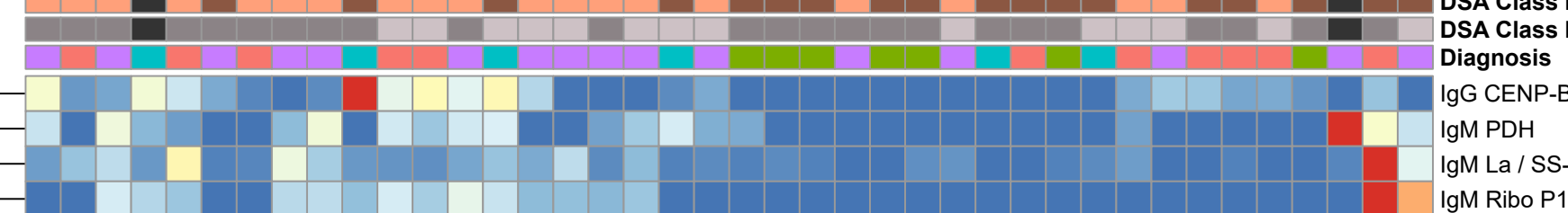

Mnmmummummumm

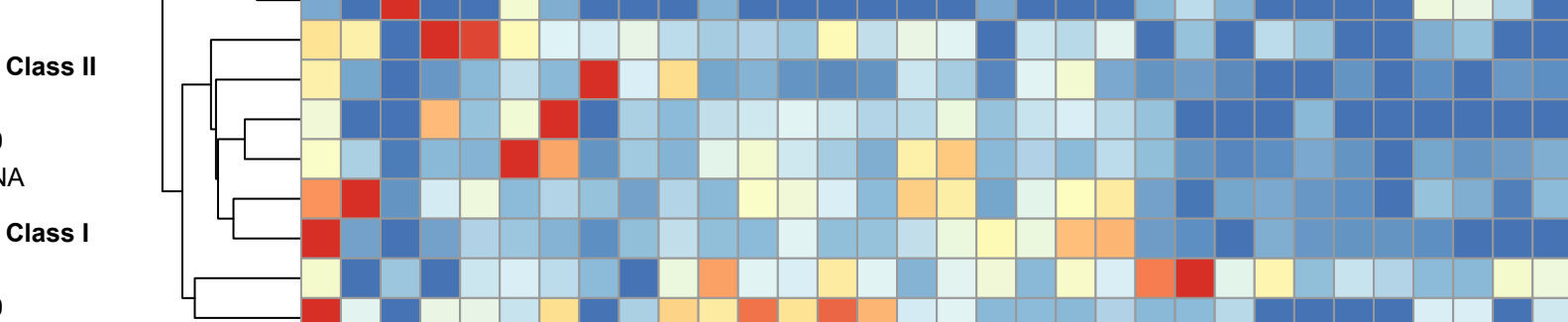

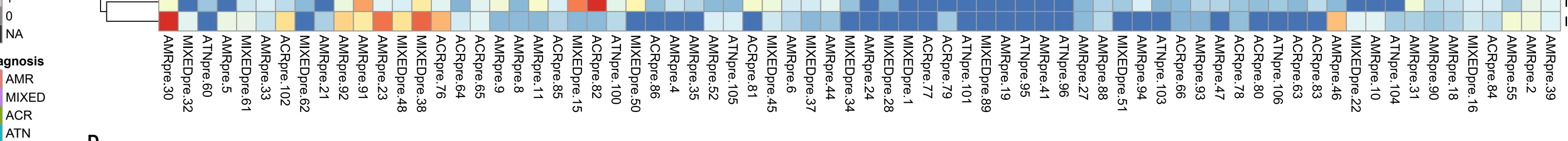

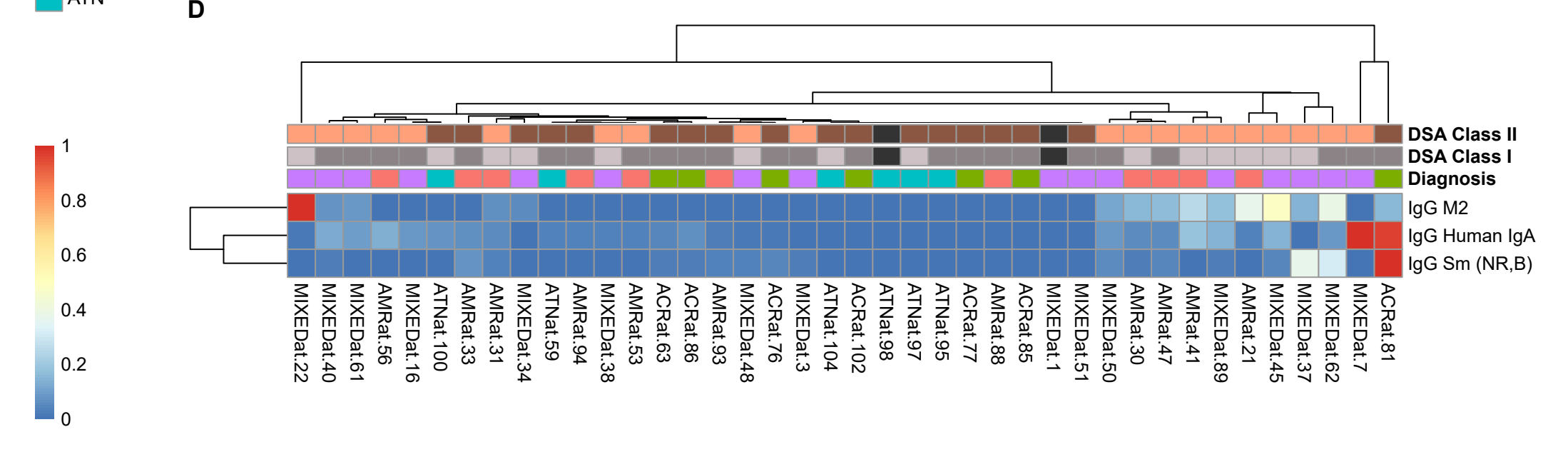

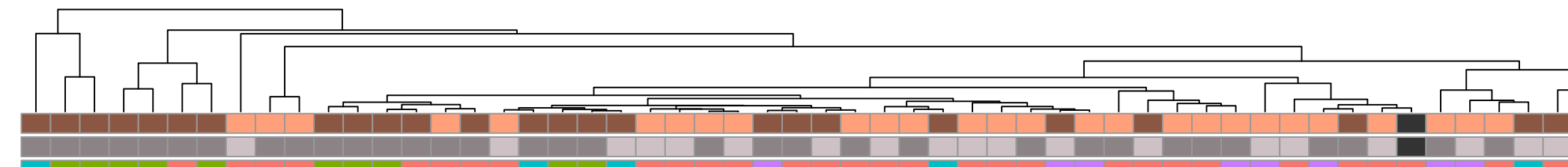

T

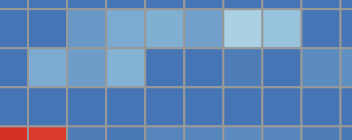

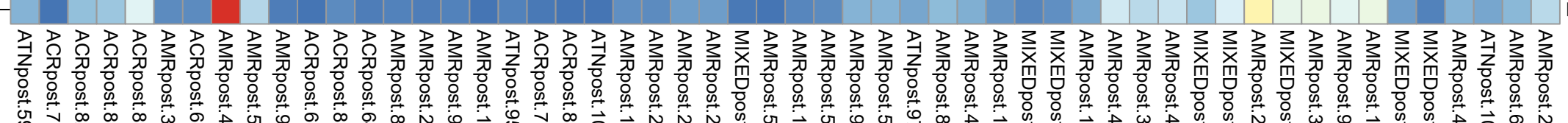

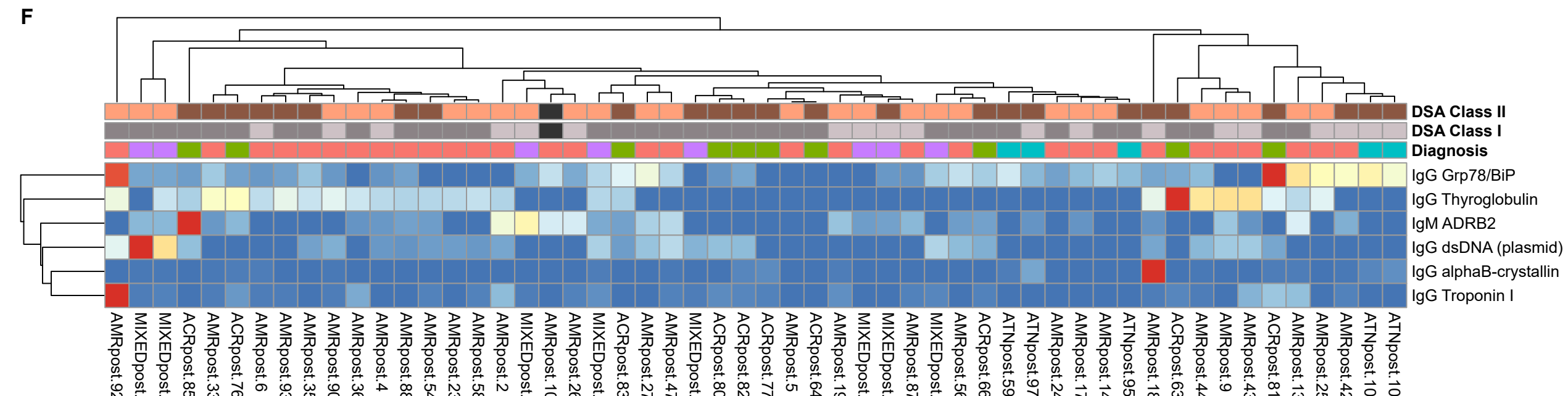




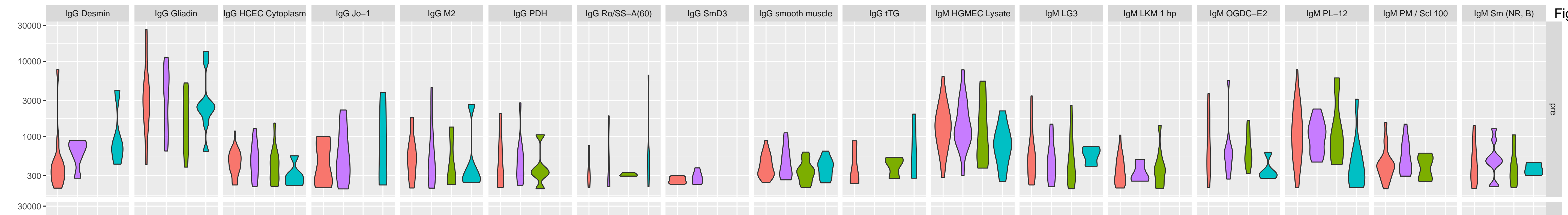

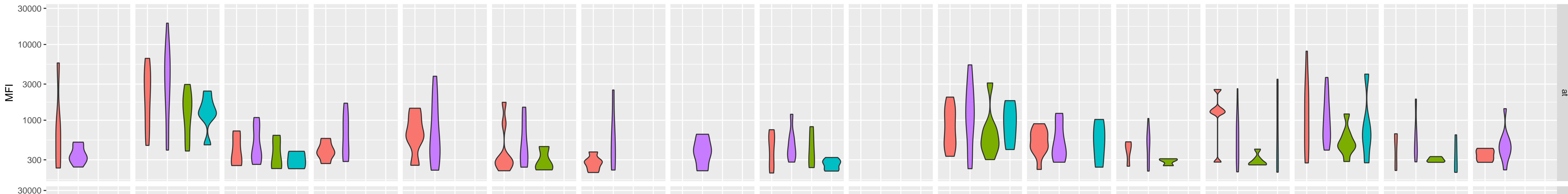
sola 
Antibody

- IgG CENP-B

- $\operatorname{lgG}$ Desmin

- $\lg \mathrm{G}$ Gliadin
IgG HCEC Cytoplasm

- IgG HCEC Cytop

- $\lg G$ Human $\lg A$

- $\lg \mathrm{G} \mathrm{Jo}-1$
- $\lg \mathrm{G} 2$

- $\lg G \mathrm{PDH}$

- IgG Ro/ SS-A (52 KDa)

- IgG Ro/ SS-A (60KDa, R)

- $\lg \mathrm{Sm}(\mathrm{NR}, \mathrm{B})$

- $\lg G \mathrm{SmD3}$

- $\operatorname{lgG}$ smooth muscle
Antibody

- IgM CENP-B

IgM HGMEC LyS

- $\operatorname{lgM} L \mathrm{LG}$

- $\operatorname{lgM}$ LKM $1 \mathrm{hp}$

- IgM OGDC-E2

- IgM PDH

- $\operatorname{lgM}$ PL-12
$\operatorname{lgM}$ PM / Scl 100

- $\operatorname{lgm}$ Ribo P1

- $\operatorname{lgm} \mathrm{Sm}(\mathrm{NR}, \mathrm{B})$ 
\begin{tabular}{|l|l|l|l|l|}
\hline $\lg G$ Beta 2-Glyc & $\lg$ G human $\lg G$ F(ab)2 & $\lg$ TPO & $\lg$ G Tropomyosin & $\lg \mathrm{G}$ tTG \\
\hline
\end{tabular}

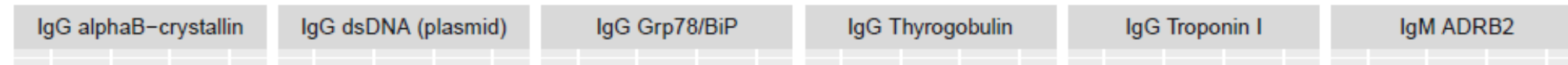

Figure S5

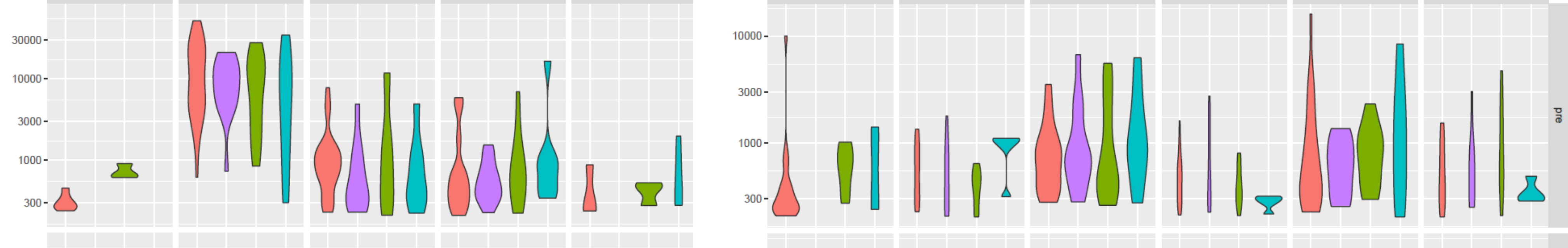

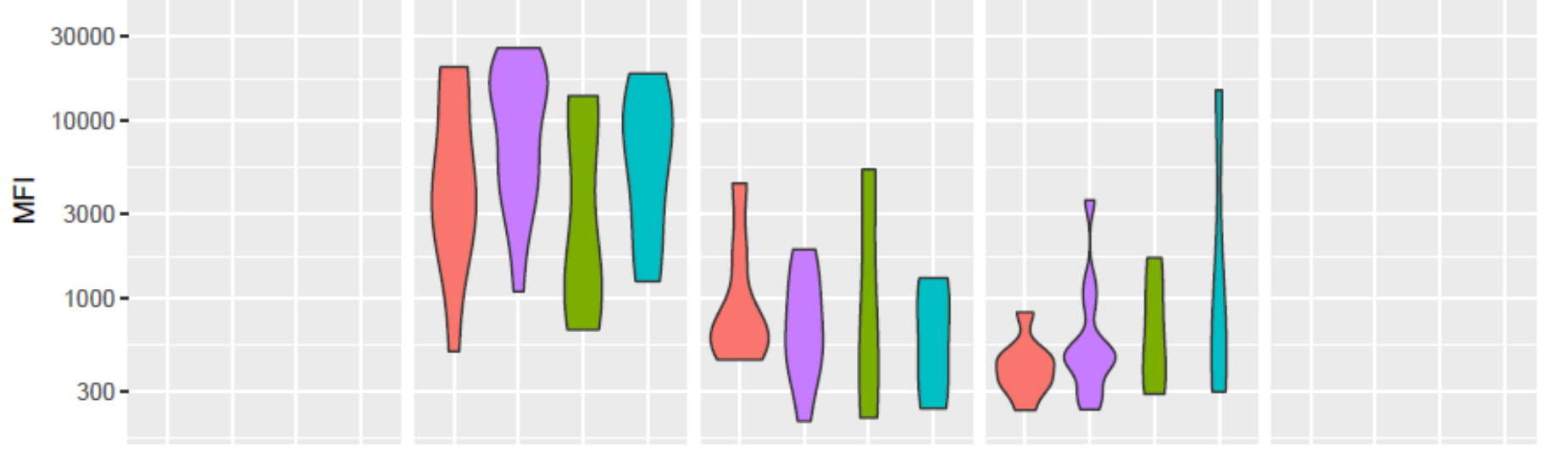

-

䀱

$\equiv|N|$

$\left.{ }_{B}{ }^{\prime}||_{Y}\right|_{\Delta} \mid$

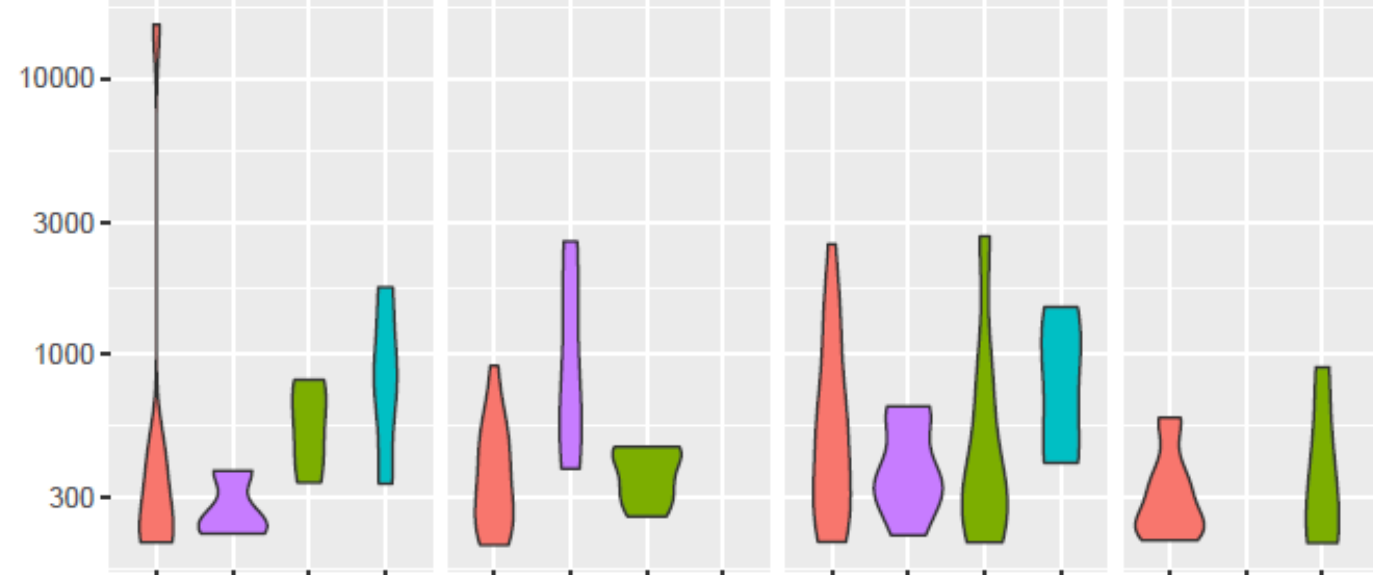

$\mid$

: 